\title{
The importance of molecular characters when morphological variability hinders diagnosability: systematics of the moon jellyfish genus Aurelia (Cnidaria: Scyphozoa)
}

\author{
Jonathan W Lawley ${ }^{\text {Corresp., } 1,2}{ }^{2}$, Edgar Gamero-Mora ${ }^{1}$, Maximiliano M Maronna ${ }^{1}$, Luciano M Chiaverano ${ }^{3}$, Sérgio N \\ Stampar $^{4}$, Russell R Hopcroft ${ }^{5}$, Allen G Collins ${ }^{6}$, André C Morandini ${ }^{1,7}$ \\ ${ }^{1}$ Departamento de Zoologia, Instituto de Biociências, Universidade de São Paulo, São Paulo, São Paulo, Brazil \\ 2 School of Environment and Science, Coastal and Marine Research Centre, Australian Rivers Institute, Griffith University, Gold Coast, Queensland, \\ Australia \\ 3 Instituto Nacional de Investigación y Desarrollo Pesquero, Mar del Plata, Buenos Aires, Argentina \\ 4 Departamento de Ciências Biológicas, Faculdade de Ciências e Letras, Universidade Estadual Paulista, Assis, São Paulo, Brazil \\ ${ }^{5}$ College of Fisheries and Ocean Sciences, University of Alaska - Fairbanks, Fairbanks, Alaska, United States \\ 6 National Systematics Laboratory of the National Oceanic and Atmospheric Administration Fisheries Service, National Museum of Natural History, \\ Smithsonian Institution, Washington, District of Columbia, United States \\ 7 Centro de Biologia Marinha, Universidade de São Paulo, São Sebastião, São Paulo, Brazil \\ Corresponding Author: Jonathan W Lawley \\ Email address: jonathan.wanderleylawley@griffithuni.edu.au
}

Cryptic species have been detected across Metazoa, and while no apparent morphological features distinguish them, it should not impede taxonomists from formal descriptions. We accepted this challenge for the jellyfish genus Aurelia, which has a long and confusing taxonomic history. We demonstrate that morphological variability in Aurelia medusae overlaps across very distant geographic localities. Even though some morphological features seem responsible for most of the variation, regional geographic patterns of dissimilarities are lacking. This is further emphasized by morphological differences found when comparing lab-cultured Aurelia coerulea medusae with the diagnostic features in its recent redescription. Previous studies have also highlighted the difficulties in distinguishing Aurelia polyps and ephyrae, and their morphological plasticity. Therefore, mostly based on genetic data, we recognize 28 species of Aurelia, of which seven were already described, 10 are formally described herein, four are resurrected and seven remain undescribed. We present diagnostic genetic characters for all species and designate type materials for newly described and some resurrected species. Recognizing moon jellyfish diversity with formal names is vital for conservation efforts and other studies. This work clarifies the practical implications of molecular genetic data as diagnostic characters, and sheds light on the patterns and processes that generate crypsis. 


\section{The importance of molecular characters when}

2 morphological variability hinders diagnosability:

3 systematics of the moon jellyfish genus Aurelia

4 (Cnidaria: Scyphozoa)

5

6 Jonathan W Lawley ${ }^{1,2}$, Edgar Gamero-Mora ${ }^{1}$, Maximiliano M Maronna ${ }^{1}$, Luciano M

7 Chiaverano $^{3}$, Sérgio N Stampar ${ }^{4}$, Russell R Hopcroft ${ }^{5}$, Allen G Collins ${ }^{6}$, André C Morandini ${ }^{1,7}$

${ }^{1}$ Departamento de Zoologia, Instituto de Biociências, Universidade de São Paulo, São Paulo, Brazil

${ }^{2}$ School of Environment and Science, Coastal and Marine Research Centre, Australian Rivers Institute, Griffith University, Gold Coast, Queensland, Australia

${ }^{3}$ Instituto Nacional de Investigación y Desarrollo Pesquero, Mar del Plata, Buenos Aires, Argentina

${ }^{4}$ Departamento de Ciências Biológicas, Faculdade de Ciências e Letras, Universidade Estadual Paulista, Assis, São Paulo, Brazil

${ }^{5}$ College of Fisheries and Ocean Sciences, University of Alaska - Fairbanks, Fairbanks, Alaska, United States

${ }^{6}$ National Systematics Laboratory of the National Oceanic and Atmospheric Administration Fisheries Service, National Museum of Natural History, Smithsonian Institution, Washington, District of Columbia, United States

${ }^{7}$ Centro de Biologia Marinha, Universidade de São Paulo, São Sebastião, São Paulo, Brazil

Corresponding Author:

Jonathan W Lawley ${ }^{1,2}$

Parklands Drive, Gold Coast, Queensland, 4222, Australia

Email address: jonathan.wanderleylawley@griffithuni.edu.au 


\section{Abstract}

42 Cryptic species have been detected across Metazoa, and while no apparent morphological

43 features distinguish them, it should not impede taxonomists from formal descriptions. We 44 accepted this challenge for the jellyfish genus Aurelia, which has a long and confusing 45 taxonomic history. We demonstrate that morphological variability in Aurelia medusae overlaps 46 across very distant geographic localities. Even though some morphological features seem 47 responsible for most of the variation, regional geographic patterns of dissimilarities are lacking.

48 This is further emphasized by morphological differences found when comparing lab49 cultured Aurelia coerulea medusae with the diagnostic features in its recent redescription.

\section{Introduction}

\section{Challenges in $21^{\text {st }}$ century taxonomy}

As genetic datasets necessary for species delimitation have grown, "integrative taxonomy" that explicitly incorporates molecular data (Dayrat, 2005) is becoming more common. Yet, taxonomy has always been integrative, relying on a broad range of available data that expand with the advent of new technologies, and it is no surprise that derived biological information should also be included (Valdecasas et al., 2008). That said, it is important to note that integration should be conducted with thoughtfulness and rigor in order to assess the utility of different lines of evidence and their use for constructing species hypotheses (Valdecasas et al., 2008; Conix, 2018). For example, DNA barcoding has been proposed as a tool for rapid species identification (Hebert et al., 2003, 2004), but the term 'species identification' has not had a standard meaning in the barcoding literature (Goldstein and DeSalle, 2011; Collins and Cruickshank, 2013; De Salle and Goldstein, 2019). Further issues relate to adherence of arbitrary distance thresholds (Wiemers and Fiedler, 2007), incomplete reference databases, misidentified sequences and more (Collins and Cruickshank, 2013; Ransome et al., 2017; Paz and Rinkevich, 2020). In spite of these complications, improvements have been made to optimize identification thresholds and assess their viability for certain groups (Virgilio et al., 2012), and it cannot be denied that molecular data have proven vital to the discovery of cryptic species, which are two or more distinct species previously unrecognized due to apparent or real morphological resemblance (Bickford et al., 2007). 
80

81

82

83

84

85

86

87

88

89

90

91

92

93

94

95

96

97

98

99

100

101

102

103

104

105

106

107

108

109

110

111

112

113

114

115

116

117

118

119

Cryptic species seem to occur across all metazoan groups and biogeographic zones, although some studies have suggested phylogenetic and ecological patterns in the distribution of this phenomenon (Bickford et al., 2007; Pfenninger and Schwenk, 2007). However, it is questionable whether cryptic species have been studied thoroughly and broadly enough across taxa to confidently assert such patterns (Trontelj and Fišer, 2009). Indeed, it seems overly simplistic to generalize about cryptic species diversity at the level of phylum, as there is an astounding variety of speciation-related processes that occur at the genus level (Trontelj and Fišer, 2009; see Coyne and Orr, 2004). Lack of morphological characters that can adequately distinguish species should be researched further to deepen understanding of morphological variation and the scope and scale of cryptic diversity. The challenge is particularly acute when one shifts from species delimitation to species description. Recognizing real rather than apparent diversity is essential not only for conservation efforts to define priorities and avoid local extinctions, but also for understanding patterns of, and processes that generate, crypsis (see review in Bickford et al., 2007 and further discussions in Struck et al., 2017).

\section{From species delimitation to description}

Taxonomy remains incomplete if discovered entities are not formally described, and species hypotheses are flagged as merely putative, creating parallel worlds populated by numbered candidate taxa (Jörger and Schrödl, 2013). The collapse of taxonomic expertise creates a sense of urgency and increasing reliance on molecular data as the solution for sustainable identification (Hebert et al., 2003). If that is the case, we must reconcile the precise mechanics of these data with the empirical and philosophical rigor of systematics and taxonomy (Goldstein and DeSalle, 2011). Without formal descriptions and testable hypotheses represented by unambiguous names, discovered species are not properly documented, and often not associated to vouchered specimens deposited at museums. Confusion arises from informal naming or numbering schemes of detected lineages when formal taxonomic practice is side-stepped, thereby limiting biodiversity analyses (Jörger and Schrödl, 2013; Pleijel et al., 2008). Many attempts have been made to incorporate DNA sequence information in taxonomic descriptions, such as including GenBank accession numbers, DNA barcode sequences, raw distance measures and phenetic or phylogenetic trees, but rarely are diagnostic sequence characters identified (see reviews and operational terminology in Goldstein and DeSalle, 2011, DeSalle and Goldstein, 2019). Nevertheless, a consensus view holds that species descriptions should be character-based (Bauer et al., 2011).

Even though it may be artificial to assume that the biological reality of a species depends on a number of diagnostic characters, it provides a falsifiable and comparable framework in which to construct and assess species hypotheses (Grant et al., 2006; Bauer et al., 2011). Furthermore, the inclusion of diagnostic characters is required for new species names by the International Code of Zoological Nomenclature (further treated as ICZN; 1999, Article 13.1.1., also see definition for 'character' in its Glossary). There are now computational tools that can provide diagnostic molecular genetic characters, such as CAOS (Sarkar, 2008), YBYRÁ 
120 (Machado, 2015), QUIDDICH (Kühn and Haase, 2019) and DeSignate (Hütter et al., 2020).

121 Even though these programs compile and evaluate diagnostic characters under different

122 strategies, which are yet to be rigorously assessed, they provide a basis for the description of

123 cryptic species. Some efforts have already been made to describe cryptic species (Jörger and

124 Schrödl, 2013; Delić et al., 2017), and even though there is an ongoing increase in recognition of

125 the economic and ecological importance of scyphozoan jellyfishes (Hamilton, 2016; Hays et al.,

126 2018), a relative lack of investment still results in a taxonomic impediment today (Goméz-Daglio

127 and Dawson, 2019).

128

129

\section{A scyphozoan jellyfish with a long taxonomic history}

130 In the moon jellyfish genus Aurelia, the subject of the present study, taxonomic history dates

131 back to the $18^{\text {th }}$ century, starting with the description of the type species Aurelia aurita

132 (Linnaeus, 1758). Since then, this genus has encompassed as many as eight (Haeckel, 1880), 13

133 (Mayer, 1910, considering varieties) or seven accepted species (Kramp, 1961). More recently,

134 only two species were recognized, Aurelia limbata Brandt, 1835, which has a brown bell margin

135 and is primarily from temperate regions, and a cosmopolitan nearshore inhabitant $A$. aurita,

136 which included as synonyms most of the previously proposed names (Larson, 1990; Arai, 1997).

137 In the 2000s, two species (Aurelia labiata Chamisso and Eysenhardt, 1821 and Aurelia

138 marginalis Agassiz, 1862) were resurrected based on morphological and geographical

139 differences (Gershwin, 2001; Calder, 2009), and with the inclusion of genetic data, there were

140 indications of at least another 16 species, some of which are hypothesized to have been

141 introduced in several localities (Dawson and Jacobs, 2001; Schroth et al., 2002; Dawson et al.,

142 2005; Goméz-Daglio and Dawson, 2017). The most recent accounts of valid described species is

143 up to 10 (Jarms and Morandini, 2019; Collins et al., 2020).

144 In addition to the evaluation of genetic data, other studies have also reassessed

145 morphological features, taking into consideration morphometric data and not only in the medusa

146 stage (Dawson, 2003), but also in other life cycle stages, such as polyps and ephyrae (Gambill

147 and Jarms, 2014). A recent result of the integration of these morphological reassessments with

148 genetic data delimited and described or redescribed three species that occur in the Mediterranean,

149 Aurelia coerulea von Lendenfeld, 1884, Aurelia relicta Scorrano, Aglieri, Boero, Dawson and

150 Piraino, 2016 and Aurelia solida Browne, 1905 (Scorrano et al., 2016). However, some of the

151 reported diagnostic morphological features seemed to overlap across these species, and

152 morphological variability was shown to be considerable, especially in the redescribed $A$.

153 coerulea (see Fig. 6 in Scorrano et al., 2016). Other findings further highlight the widespread

154 potential for high morphological variability, such as ecophenotypic plasticity in Aurelia medusae

155 (Chiaverano et al., 2016), as well as in the other stages of the life cycle (Chiaverano and

156 Graham, 2017).

157 In the present study, we re-examine the use of morphological data in Aurelia medusae,

158 the most conspicuous and collected of the life cycle stages, as well as present a molecular genetic

159 phylogeny for the genus, based on mitochondrial and nuclear markers. In addition, we evaluate

PeerJ reviewing PDF | (2021:04:60391:1:0:NEW 8 Jul 2021) 
160 previous morphological diagnoses proposed for Aurelia species. In combination with recorded

161

162

163

164

165

166

167

168

169

170

171

172

173

174

175

176

177

178

179

180

181

182

183

184

185

186

187

188

189

190

191

192

193

194

195

196

197

198

199 geographic distributions, this dataset provides a framework to delimit and describe species, as well as identify new geographical occurrences and potential introductions. With this study, we hope to encourage the transition from species delimitation to description, advance discussions on theoretical and practical applications related to diagnosis from molecular data as part of taxonomy, and expand perspectives for morphological studies to address questions regarding morphological variability, ecophenotypic plasticity, and the evolution of cryptic diversity.

\section{Materials \& Methods}

\section{Morphological data collection}

Observations were made on living medusae from aquariums in the USA, and on preserved medusae from museums and universities from the USA, Brazil and Denmark. In total, 173 specimens were analyzed (Table 1; specimen vouchers, identification, sampling sites and correspondence to molecular data of specimens observed are provided in Tables S1-S2). Two live medusae from laboratory cultures at the Laboratory for Cnidarian Studies and Cultivation (University of São Paulo), identified from genetic analyses as Aurelia coerulea (presented further), were also used, but only for the purpose of a direct comparison with the species' redescription in Scorrano et al. (2016). Specimen examinations included scaled photographs and measurements of features that involved "depth" or "thickness", which could not be acquired later from photographs. When necessary, a stereomicroscope was also used for observations. Morphological measurements were acquired from scaled photographs with the program Fiji (Schindelin et al., 2012).

Characteristics observed from medusae mainly followed Dawson (2003), which included 24 characters, comprising continuous, meristic, and categorical features (Fig. 1, f1-30; Table S3). Sixteen extra characters were added (Fig. 1, f31-46; Table S3), either novel or from previous studies (Gershwin, 2001; Chiaverano et al., 2016), mainly to unambiguously characterize categorical features, after observing their variation.

\section{Morphological data analyses}

To account for differences in shape, morphology must be characterized regardless of size. As continuous and meristic features in our dataset may vary with size (i.e., bell diameter - f1), we scaled all individuals to the same fl by adapting the method of Lleonart et al. (2000), which has been previously used for various animals including jellyfish (Chiaverano et al., 2016). This method considers potential allometric differences that can occur between species or even within species across geographic localities. Specimens analyzed were therefore separated into geographic localities defined by countries, and usually also by region within the country (e.g., southeast - SE). Size corrections followed the formula $Y^{*}=Y_{i}\left(\mathrm{fl}_{m} / \mathrm{f} 1_{i}\right)^{b}$, in which the desired sizecorrected feature $\left(Y^{*}\right)$ equals its measurement in a specimen $\left(Y_{i}\right)$ times the ratio between the average bell diameter in the locality group $\left(\mathrm{fl}_{m}\right)$ and the bell diameter of the specimen $\left(\mathrm{fl}_{i}\right)$, this raised to the power of the slope of the relationship between both log-transformed variables $Y$ and 
$200 \mathrm{fl}$ from the entire dataset $(b)$, as we did not have enough samples per locality group to obtain 201 significant relationships.

202 Some morphological characters in 104 of the observed specimens were damaged,

203 missing, or could not be measured by photographs. In this case, prior to the size correction

204

205

206

207

208

209

210

211

212

213

214

215

216

217

218

219

220

221

222

223

224

225

226

227

228

229

230

231

232

233

234

235

236

237

238

239 mentioned above, we adapted Lleonart's method to perform estimations of these missing data, using the same formula as before, but considering $Y_{i}$ as the missing variable to be estimated and $Y^{*}$ as the average of the given variable in the locality group. When data for the variable were not present within the locality group, we used data from the closest locality, also accounting for morphological similarity when possible (see details in Table S1).

Features that were mostly invariable or that lacked a significant relationship with $\mathrm{f} 1$ were removed from further analyses, as they could bias the resulting dataset. Lastly, we standardized all variables to scale to a minimum of 0 and maximum of 1 . Categorical features were excluded from analyses, as they may not be reliable due to the ambiguity seen in the specimens observed. Number of lobes (f19) and number of rhopalia (f20) were also removed as not to bias the results due to potential asymmetric development that may occur in some specimens. Medusae were not differentiated based on presence or absence of gonads, and consequently not between male and female, as size is the main factor influencing variation of morphological features.

In order to compare observed specimens based on the size corrected and scaled continuous and meristic morphological characters described above, we performed multidimensional scaling (MDS, Gower distance), with weighted average scores of variable contributions also mapped within. These analyses were separated into two sets, one that included all specimens with estimated missing data and subsequent size correction and scaling of variables, and another that excluded specimens with missing data, and therefore only size corrections and scaling were performed, to check for potential biases in estimations. Regarding these analysis sets we also computed a Mantel test with 9999 permutations, to investigate the correlation between a geographic distance matrix (Euclidean distance, based on coordinates) and a morphological difference matrix (Gower distance, based on size corrected and scaled features), excluding aquarium specimens. The comparison of morphological measurements of $A$. coerulea from lab cultures and the species' redescription was performed by Welch's t-test. All of the corrections, estimations and further analyses mentioned above were performed using the software $\mathrm{R}$ version 4 (R Core Team, 2020) and relevant codes are available in GitHub (github.com/lawleyjw/Aurelia).

\section{Molecular data collection}

Total DNA was extracted from oral arms of medusae, entire polyps, or entire ephyrae from specimens collected in the field or cultured in the laboratory at the University of São Paulo, using a protocol based on ammonium acetate, adapted from Fetzner (1999) (see Table S4 for details on samples used for molecular genetic analyses). From the mitochondrial genome, we amplified and sequenced two markers: a $\sim 650$-bp fragment of the large ribosomal RNA subunit (16S) and a $\sim 650$-bp fragment of the cytochrome c oxidase subunit I (COI) (primers derived 
240 from Lawley et al., 2016). From the nuclear genome, we obtained the internal transcribed spacer

2411 (ITS1) with 300-bp in length (primers jfITS1-5F, from Dawson and Jacobs, 2001; and ITS-R-

242 28S-15, from Cunha et al., 2015), and a $\sim 650$-bp fragment from the large ribosomal RNA

243 subunit (28S) (primers Aa_L28S_260 and Aa_H28S_1078 from Bayha et al., 2010). Polymerase

244 Chain Reaction (PCR) protocols followed standard procedures. Thermocycler profiles were

245 conducted with initialization at $95^{\circ} \mathrm{C}$ for three min, followed by $36-40$ cycles of denaturation at

$24695^{\circ} \mathrm{C}$ for $30 \mathrm{~s}$, annealing at $46-58^{\circ} \mathrm{C}\left(16 \mathrm{~S}-46^{\circ} \mathrm{C}\right.$; COI $-52^{\circ} \mathrm{C}$; ITS $\left.1-57^{\circ} \mathrm{C} ; 28 \mathrm{~S}-58^{\circ} \mathrm{C}\right)$ for $30-$

$24745 \mathrm{~s}$, and extension at $72^{\circ} \mathrm{C}$ for $1-2 \mathrm{~min}$. Final extension was further conducted at $72^{\circ} \mathrm{C}$ for 10

248 min. PCR products were purified using Agencourt AMPure XP DNA Purification and Cleanup

249 kit (Beckman Coulter Inc.) and subsequently cycle-sequenced, with the same primers as before,

250 to add fluorescently labeled dideoxy terminators. The above procedures were conducted at the

251 Laboratory of Molecular Evolution (University of São Paulo) and chromatograms were

252 generated on an Applied Biosystems 3730xl DNA Analyzer at the Laboratory of Plant

253 Regulatory Network Signaling (University of São Paulo).

254

255

256

257

258

259

260

261

262

263

264

265

266

267

268

269

270

271

272

273

274

275

276

277

278

279

\section{Molecular analyses, species delimitation and descriptions}

Sequenced chromatograms were assembled, trimmed and aligned in Geneious Prime 2019.0.4 (Kearse et al., 2012), which also included most sequences available in GenBank for Aurelia and some for Drymonema dalmatinum Haeckel, 1880 (Table S4), the chosen outgroup taxa as it was the most closely related Semaeostomeae to Aurelia (Bayha et al., 2010) with sequences for all markers herein studied. Alignments were performed using the software's implementation of MAFFT (Katoh and Standley, 2013), with the G-INS-i option and other default parameters, later visualized and edited manually to remove leading and trailing gap regions from variations in sequence length. Because the $\mathrm{COI}$ alignment did not present any alternative indel positions, which is common for protein-coding regions if introns are absent, the static alignment (sensu Wheeler, 2001) generated with MAFFT was used for phylogenetic analyses. This alignment was submitted to TNT ver 1.5 (Goloboff and Catalano, 2016) and analyzed under parsimony as the optimality criterion, using its New Technology searches (Goloboff, 1999; Nixon, 1999) with the following parameters: consense 10, css, rss, xss, rep 10, ratchet 50, drift 50, fuse 10. Node support was assessed by Goodman-Bremer values (Goodman et al., 1982; Bremer, 1994; Grant and Kluge, 2008), calculated by running a modified version of the script BREMER.RUN distributed with TNT, which considered 1,000 replicates with 10 repetitions of ratchet and drift (Goloboff, 1999; Nixon, 1999) in constrained searches. Bootstrap resampling frequencies were also calculated for nodes from 1,000 pseudoreplicates.

Considering ribosomal RNA regions, they commonly present insertions and deletions, which makes multiple sequence alignment more challenging (Nagy et al., 2012). To account for this, we submitted the resulting sequences of $16 \mathrm{~S}$, ITS1 and $28 \mathrm{~S}$ to phylogenetic inference by direct optimization (Wheeler, 1996) using POY ver. 5.1.2 (Wheeler et al., 2014), under the parsimony optimality criterion. Tree search was performed by three independent one, three and six hour searches assuming equal rates for character transformations. All unique trees compiled 
280 from the above searches were submitted to tree refinement by the tree-fusing algorithm 281 (Goloboff, 1999) and re-diagnosed with the iterative pass algorithm (Wheeler, 2003a). The 282 resulting implied alignment (sensu Wheeler, 2003b) was submitted to TNT to verify the results, 283 under the same parameters as described before, including the Goodman-Bremer support and 284 bootstrap frequencies. The analyses run with POY were conducted in an IBM x3850 X5 server 285 with eight processors Intel Xeon CPU E7-8870 2.40 GHz, housed at the Genetics and Evolutionary Biology Department (University of São Paulo).

Primary species hypotheses were considered based on previous mentions in the literature and when, in at least one single-marker phylogeny, species clades were monophyletic, had support $\geq 2$ and resampling frequency $\geq 75$. Then, markers were combined for a concatenated phylogenetic analysis. We imported the 16S, ITS1 and 28S implied alignments, and the COI static alignment, to Sequence Matrix ver 1.8 (Vaidya et al., 2011), and selected mostly 3-4 sequences, when available, of each marker for each of the hypothesized species (see details of sequence composition in Table S5). Whenever possible, sequences of different markers within species were selected from the same specimen, but alternatively these sequence sets (terminal taxa) were chimeric, combined either from other specimens of the same locality, or the closest locality (Table S5). Sequence sets within each species hypothesis were selected from geographic regions as diverse as possible. The resulting file with combined alignments was analyzed in TNT as described previously. We also performed this concatenated phylogenetic analysis in IQ-TREE ver 1.6.12 (Nguyen et al., 2015) under maximum likelihood as the optimality criterion, using ModelFinder (Kalyaanamoorthy et al., 2017) for model selection and measuring bootstrap resampling frequencies and SH-aLRT (Guindon et al., 2010) from 1,000 pseudoreplicates.

303

304

305

306

307 Alignments and trees retrieved in all molecular genetic analyses were deposited in Figshare (Lawley et al., 2021). All relevant codes used for genetic analyses are available in GitHub (github.com/lawleyjw/Aurelia).

For species delimitation (sensu DeSalle and Goldstein, 2019), primary species hypotheses were reassessed based on criteria from two lines of evidence: (1) species' monophyly and the clade's support $(\geq 2)$, resampling frequency $(\geq 75)$ and branch length (ad hoc) on the concatenated phylogeny; (2) species' distribution, based on collection localities of sequenced specimens (ad hoc). However, there are some caveats to this procedure. We recognize that phylogenetic analyses impose a hierarchy even on entities related tokogenetically (Davis and Nixon, 1992;

312 do not necessarily need to form a clade (Kluge, 1990; Frost and Kluge, 1994; Skinner, 2004).

313 Therefore, branch lengths of the species' clades were also considered, as these are a measure of

314 their differentiation. Nevertheless, due to variation in evolutionary rates and collection efforts,

315 branch lengths may vary even across congeners (Grant et al., 2006). Considering species

316 distributions can also be misleading, as there are likely multiple introductions in different Aurelia 317 species (Dawson et al., 2005), as well as sympatry (Chiaverano et al., 2016). In spite of these 318 caveats, these are clear and falsifiable criteria that can facilitate species discovery (sensu DeSalle 319 and Goldstein, 2019) and diagnosability (Frost et al., 1998; Grant et al., 2006). 
After species delimitation, diagnostic characters (sensu ICZN, 1999) were identified for

321

322

323

324

325

326

327

328

329

330

331

332

333

334

335

336

337

338

339

340

341

342

343

344

345

346

347

348

349

350

351

352

353

354

355

356

357

358

359

each marker using the program YBYRÁ (Machado, 2015), considering the alignments and phylogenies of both single-marker and concatenated analyses. Reported diagnostic characterstates for positions in the alignment are color-coded in the program's output, based on optimization of synapomorphies (sensu Grant and Kluge, 2004): white are ambiguous, and other colors are unambiguous; black are unique and non-homoplastic; red are unique and homoplastic; and blue are non-unique and homoplastic (see further details in Machado, 2015).

We also calculated uncorrected pairwise distances (number of base mismatches divided by total sequence length, also known as uncorrected $p$ ), which were retrieved from the software Geneious. We did not use this measure to delimit species, as (1) pairwise distances only discriminate among samples, and therefore cannot diagnose any particular entity (Frost, 2000); (2) they fail to explain observed variation, as they cannot distinguish between symplesiomorphy and synapomorphy; and (3) due to variation in evolutionary rates that could occur even among congeners, as previously mentioned, there seems to be no justification to set an arbitrary distance as threshold for granting species status (Grant et al., 2006). Nevertheless, we evaluated the use of this measure across molecular genetic markers, as it can provide a rapid heuristic for species identification (sensu DeSalle and Goldstein, 2019) without the need of a complete phylogenetic analysis, in a similar way as dichotomous keys can be useful identification tools (Grant, 2002; Grant et al., 2006).

The electronic version of this article in Portable Document Format (PDF) will represent a published work according to the International Commission on Zoological Nomenclature (ICZN), and hence the new names contained in the electronic version are effectively published under that Code from the electronic edition alone. This published work and the nomenclatural acts it contains have been registered in ZooBank, the online registration system for the ICZN. The ZooBank LSIDs (Life Science Identifiers) can be resolved and the associated information viewed through any standard web browser by appending the LSID to the prefix http://zoobank.org/. The LSID for this publication is: urn:lsid:zoobank.org:pub:9CCDC703-92EB-4EDD-AB8FF353941FEA1B. The online version of this work is archived and available from the following digital repositories: PeerJ, PubMed Central and CLOCKSS.

\section{Results}

\section{Morphological assessment}

Before analyses were performed, morphological variation could already be observed among specimens of similar size from the same collection lot, as illustrated in Fig. 2. It is possible to see variation, for example, in the size of gastric pouches (f31) and sub-genital pores (f11a), as well as in the number of oral arm folds ( $\mathrm{f} 3 \mathrm{a}$ ).

This variation was also observed after MDS analyses (with and without estimation of missing data), as neither presented a clear geographic structure on morphological dissimilarities (Figs. 3-4; correspondence of regions in Figs. 3-4 with specimen vouchers are shown in Figs. S1S2). Specimens from lot YPM29380 from the northeastern coast of the USA for example, shown

PeerJ reviewing PDF | (2021:04:60391:1:0:NEW 8 Jul 2021) 
360 in Fig. 2, were sometimes more similar to specimens from very distant localities, such as the 361 Maldives or the Marshall Islands, than to others in the same lot (highlighted in blue in Figs. 3-4).

362 Another example of morphological resemblance among distant localities are the specimens from 363 the northeastern coast of Canada and southwestern coast of the USA (highlighted in green in 364 Figs. 3-4; Fig. 5A-D). It is possible to see the similarity in the oral arms (f5 and f7), the size of 365 the sub-genital pores (f11a) and in the branching pattern of interradial canals (f43) (Fig. 5A-D). 366 In that sense, even though some individuals within a locality or lot may appear closer in the 367 MDS, morphological variation within these groups still seem to be variable enough to overlap 368 across very distant localities (Figs. 3-4). This is further emphasized by the spread of specimens that were identified from genetic sequences as Aurelia coerulea (presented further; highlighted in orange in Figs. 3-4). The only example in which many specimens from the same locality group are clustered separately, is in the case of $A$. coerulea individuals analyzed from the aquarium at Discovery Place, USA (circled in orange in Figs. 3-4). The only other specimens observed that could be identified from genetic sequences were three individuals from southeastern Brazil, two Aurelia cebimarensis sp. nov. (presented further; highlighted in pink in Figs. 3-4), and one Aurelia mianzani sp. nov. (presented further; highlighted in red in Fig. 3).

Even though there is no apparent geographic structure in dissimilarities, some of the measured characters seem to be more variable across all analyzed specimens, which are represented closer to the edges of the morphological scape in the MDS (Figs. 3-4, characters in red). Specimens represented closer to these characters do not necessarily have the greatest values for it, but that character is the one that most contributed for the specimen's position in the MDS. Individuals from the aquarium at Discovery Place (circled in orange in Figs. 3-4) for example, seem to have the greatest distance between proximal edges of opposing gastric pouches, as well as between proximal tips in each gastric pouch (f9 and f35, respectively; Fig. 6A; Tables S1-S2). Rhopaliar and non-rhopaliar indentations ( $\mathrm{f} 29$ and $\mathrm{f} 30$, respectively) are the largest in some specimens from Brazil (Fig. 6B) and one from the Philippines (brown square in Figs. 3-4; Tables S1-S2). Some specimens from the Arctic (Fig. 6C) and a specimen from Japan have the highest number of perradial and interradial branching points ( $\mathrm{f} 42$ and $\mathrm{f} 43$, respectively; black squares in Figs. 3-4), although it is also high in some specimens from the southwestern coast of the USA, and seems to contribute greatly for their position (Figs. 3-4; Tables S1-S2). In the same way, a specimen from northwestern Canada has the highest number of interradial terminations (f40; grey square in Figs. 3-4; Fig. 6D), although it is also high in a specimen from Cuba, contributing greatly to its position (Figs. 3-4; Tables S1-S2). The number of perradial terminations (f39), on the other hand, is higher in a specimen from the Philippines (underlined in brown in Figs. 3-4; Tables S1-S2).

If specimens from neighboring localities had distinguishable morphological features, it could be argued that morphotypes could be identified regionally. The Mantel test revealed a different pattern, with a weak positive correlation in which specimens from nearby localities are more similar to each other compared to more distant localities, although only significant for the 
399

400

401

402

403

404

405

406

407

408

409

410

411

412

413

414

415

416

417

418

419

420

421

422

423

424

425

426

427

428

429

430

431

432

433

434

435

436

437

438

dataset with estimation of missing data $\left(\mathrm{R}^{2}=0.067, \mathrm{p}<0.05\right.$; without estimation of missing data, $\left.\mathrm{R}^{2}=0.083, \mathrm{p}>0.05\right)$.

\section{Morphological variability and diagnosis in Aurelia coerulea}

In view of the high morphological variability observed, we compared the diagnostic features presented in the A. coerulea redescription, based on seven to 10 Mediterranean specimens (for more details see Table 2 in Scorrano et al., 2016), with two medusae from lab cultures (polyps originally from the North Sea) that were identified from genetic sequences as A. coerulea (presented further). By comparing Fig. 7A, C, some morphological differences can already be perceived, and this is further emphasized in Fig. 8, which highlights the significant differences in the continuous and meristic characters measured. Also, specimens cultured in the lab had a rounded hood covering the rhopalia, while Mediterranean specimens presented a triangular hood (Fig. 7B, D).

\section{Species delimitation}

The concatenated phylogenetic analysis, which combined all markers herein studied (16S, COI, ITS1 and 28S), revealed 28 species hypotheses (Fig. 9), of which seven had already been described and are currently recognized as valid (A. marginalis, A. solida, A. labiata, A. relicta, A. aurita, A. coerulea and A. limbata; based on Collins et al., 2020). Of the 21 remaining, two were collected and sequenced in this study for the first time (Aurelia ayla sp. nov. and Aurelia insularia sp. nov.), and eight had been previously sequenced or even considered as species hypothesis but not formally described (Aurelia miyakei sp. nov., Aurelia mianzani sp. nov., Aurelia rara sp. nov., Aurelia montyi sp. nov., Aurelia smithsoniana sp. nov., Aurelia cebimarensis sp. nov., Aurelia malayensis sp. nov. and Aurelia columbia sp. nov.). Four species were resurrected (Aurelia clausa Lesson, 1830, Aurelia dubia Vanhöffen, 1888, Aurelia persea (Forskål, 1775) and Aurelia hyalina Brandt, 1835) and the other seven remain undescribed (sp. 3, $7,12,13,14,17$ and 18), as their distributions did not match any available names, or there was either no type material available or they were already under description. A map of type localities (or sampling localities in the case of undescribed species) for Aurelia species hypotheses is shown in Fig. 10, while the distribution ranges are described in the 'Systematic account' section (for specific localities of sequenced specimens see Table S4).

In the concatenated phylogeny, counts of diagnostic genetic characters within each unambiguous synapomorphy category are represented for species clades (Fig. 9). Six of the 28 species hypothesized do not present unique and non-homoplastic synapomorphies (in black, Fig. 9), which does not seem to be related to clade support, resampling frequency or branch length. Nevertheless, there were synapomorphies present in at least one of the unambiguous categories for every species. Ten species had sequences of the four genetic markers used for at least one sequence set (terminal taxon) in the concatenated phylogenetic analysis (circles with grey or black coloring for every quarter in Fig. 9). Complete sequence sets (with sequences of all markers) represented $30 \%$ of terminal taxa (see completeness ratios in Table S5). Non-chimeric 
sequence sets (only containing sequences from the same specimen) represented $49 \%$ of terminal taxa, and within the chimeric sequence sets an average of $60 \%$ of sequences within a set were not from the same specimen (see chimerism ratios in Table S5).

A concatenated phylogenetic analysis was also performed using maximum likelihood as the optimality criterion, in which some relationships between species differ from the parsimony analysis but species hypotheses are the same (Fig. S3). Single-marker phylogenies, which were used to construct primary species hypothesis, are represented in Figs. S4-S7, and the diagnostic synapomorphies derived from these are included as counts for each species in the 'Systematic account' section (diagnostic positions for each species can be found in Table S6). Considering uncorrected pairwise distances, they are reported for single-marker alignments as frequency histograms in Fig. 11. There was an overlap between intra- and interspecific distances for all markers, although COI was the marker that presented an overall gap between intra- and interspecific distances (Fig. 11; for details on intra- and interspecific distances for each marker see Table S7). Nevertheless, ITS1 had the greatest number of unique and non-homoplastic synapomorphies when comparing single-marker analyses, while COI had the least amount (Table S6). As with synapomorphies in the concatenated phylogenetic analysis, not all species hypotheses recovered in single-marker analyses had unique and non-homoplastic synapomorphies (Table S6).

\section{Systematic account}

Phylum Cnidaria Verrill, 1865

Class Scyphozoa Goette, 1887

\section{Order Semaeostomeae Agassiz, 1862}

Family Ulmaridae Haeckel, 1880

Genus Aurelia Lamarck, 1816

Diagnosis: Ulmarid scyphomedusae with unbranched oral arms surrounding the mouth; interradial gastric pouches with much folded gonads (when present), unconnected from each other and with external subgenital pores, usually ranging in shape from a flat-u to a drop-shaped invagination; radial canals branching and sometimes anastomosing, extending outwards to margin from central stomach; ring canal present; lappet-like structures and numerous (commonly more than 1,000) small tentacles arising from exumbrella just above the margin; marginal rhopalia usually on the center of the perimeter of each radius, commonly resulting on a bell indentation (marginal cleft) that marks the division between velar lobes; non-rhopaliar indentations can be present and therefore increase divisions between velar lobes; usually presents tetramerous radial symmetry (compiled from Mayer, 1910; Kramp, 1961; Russell, 1970; Calder, 2009; Scorrano et al., 2016; Jarms and Morandini, 2019; and own observations).

Type species: Aurelia aurita (Linnaeus, 1758) 
478

479

480

481

482

483

484

485

486

487

488

489

490

491

492

493

494

495

496

497

498

499

500

501

502

503

504

505

506

507

508

509

510

511

512

513

514

515

Species hypotheses are presented below in the order they appear in the concatenated phylogenetic analyses, from top to bottom (Fig. 9). For precise localities of sequenced specimens, see Table S4. Molecular genetic diagnosis, with details on synapomorphy categories and positions are given in Table S6. A brief morphological description is provided, when available, for all life cycle stages of species considered herein (Table S8).

Aurelia ayla Lawley, Gamero-Mora, Maronna, Chiaverano, Stampar, Hopcroft, Collins and Morandini sp. nov.

Type material: Holotype: Tissue (Medusa), USNM 1622161. Paratype: Tissue (Medusa), USNM 1622169.

Type locality: Oil slick leap, Kralendijk, Bonaire, the Netherlands (Fig. 10).

Etymology: Derived from the Turkish word ayla, meaning "halo of light around the moon", in honor of the daughter of AGC (co-author in this study), who shares the same name.

Distribution: Currently known only from the type locality (Table S4).

Diagnosis: There were 20 diagnostic positions for $16 \mathrm{~S}$ and 20 for COI (Table S6).

Remarks: Interestingly, this species does not fall within the clade that includes most western Atlantic species. Further increasing the dataset with more molecular genetic markers and specimen collections, especially from the southeastern Atlantic and Indian Oceans, could resolve this matter, as it could not only be an effect of undersampling but also a case of introduction from another locality, which is not unprecedented in this genus (Dawson et al., 2005). For a brief morphological description of the medusa stage see Table S8.

Aurelia miyakei Lawley, Gamero-Mora, Maronna, Chiaverano, Stampar, Hopcroft, Collins and Morandini sp. nov.

Aurelia MCA lineage Schroth et al., 2002. Dawson et al., 2005.

Aurelia sp. 11 Dawson et al., 2005. He et al., 2015; Chiaverano et al., 2016; Dong, 2018. 8655.

Type material: Holotype: Polyps, MZUSP 8654. Paratypes: Tissue (Polyps), MZUSP

Type locality: Gulf of Thailand, near Saen Suk, Thailand (Fig. 10).

Etymology: Named after Prof. Dr. Hiroshi Miyake (Kitasato University, Japan), for his prominent research on jellyfish and constant collaborative efforts, including providing polyps from this species.

Distribution: Gulf of Thailand and Kwajalein, Marshall Islands (Table S4).

Diagnosis: There were 17 diagnostic positions for 16S, 20 for COI, 20 for ITS1 and 17 for 28S (Table S6). 
516

517

518

519

520

521

522

523

524

525

526

527

528

529

530

531

532

533

534

535

536

537

538

539

540

541

542

543

544

545

546

547

548

549

550

551

552

553

554

555

Remarks: Polyps were present in collected material from nearby the Institute of Marine Science, Burapha University, Saen Suk, Thailand. For a brief morphological description of the polyp stage see Table S8.

Aurelia insularia Lawley, Gamero-Mora, Maronna, Chiaverano, Stampar, Hopcroft, Collins and Morandini sp. nov.

Aurelia sp. 2 Gambill and Jarms, 2014.

Type material: Holotype: Polyps, MZUSP 8648. Paratypes: Polyps, MZUSP 8647; Tissue (Polyps), MZUSP 8649.

Type locality: Pinguino Wreck, Ilha Grande, Rio de Janeiro, Brazil (Fig. 10).

Etymology: Derived from the Latin word insularis, meaning "of islands", in reference to the recorded occurrence of polyps mostly on or near islands.

Distribution: Mostly on or near islands in the south and southeastern coasts of Brazil, as well as on Key Largo, Florida, USA (Table S4).

Diagnosis: Polyps present 27-33 tentacles (Table S8; see remarks below). There were 20 diagnostic positions for 16S, 20 for COI, 20 for ITS1 and 11 for 28S (Table S6).

Remarks: Polyps of this species were first collected in Ilha Grande, Rio de Janeiro, in 2000, by Prof. Dr. Alvaro E. Migotto (CEBIMar-USP, Brazil). After Dawson and Jacobs (2001) identified sequences of medusae from the coast of São Paulo state as Aurelia sp. 2 (herein described as Aurelia cebimarensis sp. nov.), polyps from Ilha Grande were also assigned to this species. Gambill and Jarms (2014), in their study of Aurelia scyphistomae and ephyrae, also recognized the polyps from Ilha Grande as $A$. sp. 2, and it was the only population that had 27-33 tentacles, while all others in the study presented $\sim 16$ tentacles. This remains as the only morphological diagnostic character for this species, even though morphological plasticity has also been reported in Aurelia polyps and ephyrae (Chiaverano and Graham, 2017). Nevertheless, there are unambiguous molecular genetic characters to support this species' diagnosis. More recently, this species was detected on Key Largo (Florida, USA) with the use of eDNA techniques (Ames et al., 2021). For a brief morphological description of the polyp and ephyra stages see Table S8.

Aurelia mianzani Lawley, Gamero-Mora, Maronna, Chiaverano, Stampar, Hopcroft, Collins and Morandini sp. nov.

Aurelia sp. AA2501 South West Atlantic Ramšak et al., 2012.

Aurelia sp. 16 Gómez-Daglio and Dawson, 2017. Abboud et al., 2018; Dong, 2018.

Type material: Holotype: Medusa, MZUSP 8652. Paratype: Tissue (Medusa), MZUSP 8653. 
556

557

558

559

560

561

562

563

564

565

566

567

568

569

570

571

572

573

574

575

576

577

578

579

580

581

582

583

584

585

586

587

588

589

590

591

592

593

594

595

Type locality: Praia do Segredo, São Paulo, Brazil (Fig. 10).

Etymology: In honor of Dr. Hermes W. Mianzan (INIDEP, Argentina), who collected some of the sequenced specimens of this species, and for his lifelong contributions and dedication to understanding jellyfish biology and ecology in the Southwestern Atlantic.

Distribution: Praia do Segredo, São Paulo, Brazil and Bahía Samborombón, Buenos Aires, Argentina (Table S4).

(Table S6).

Diagnosis: There were 10 diagnostic positions for $16 \mathrm{~S}, 19$ for COI and five for $28 \mathrm{~S}$

Remarks: In Ramšak et al. (2012), the specimen collected in the Southwestern Atlantic appeared as sister taxa to a specimen from the Mljet lakes, Croatia (currently known as Aurelia relicta), in their combined-marker phylogeny. In our single-marker phylogenies, we observed that the COI sequence from that study fell within a clade alongside the other sequences from Argentina (Fig. S5), while the ITS1 sequence from that same specimen fell within the $A$. relicta clade (Fig. S6). This could be explained by contamination in sequencing the ITS1, as in the aforementioned study, A. relicta specimens from the Mljet lakes were also being processed. As other sequences from Argentina were available, the specimen from Ramšak et al. (2012) was disregarded from our concatenated phylogenetic analysis.

Interestingly, this species forms a clade that is sister to the clade containing both Aurelia sp. 12 and Aurelia sp. 13 from the eastern Pacific, all nested within a clade shared by most western Atlantic species (Fig. 9). This diversification across the Isthmus of Panama has been reported for other cnidarians (Stampar et al., 2012; Goméz-Daglio and Dawson, 2017). Further biogeographical studies and increased sampling can verify this matter, as well as the curious position of the other eastern Pacific species Aurelia sp. 14 on the concatenated phylogeny (Fig. 9). For a brief morphological description of the medusa stage see Table S8.

Aurelia rara Lawley, Gamero-Mora, Maronna, Chiaverano, Stampar, Hopcroft, Collins and Morandini sp. nov.

Aurelia sp. DI'03-4 Chiaverano et al., 2016.

Type material: Holotype: Tissue (Medusa), USNM 1643584. Paratype: Tissue (Medusa), USNM 1643585.

Type locality: Dauphin Island, Alabama, United States of America (Fig. 10).

Etymology: Derived from the Latin word rarus, meaning "rare" or "uncommon", due to its elusive occurrence among the other two species collected in the same locality (Aurelia montyi sp. nov. and Aurelia marginalis, herein considered).

Distribution: Currently known only from the type locality (Table S4).

Diagnosis: There were six diagnostic positions for 16S and 18 for COI (Table S6).

Remarks: Chiaverano et al. (2016) sequenced one specimen from Dauphin Island (DI'03-4), which in their COI phylogeny did not group with any other species, while in the ITS1 
596 phylogeny fell within A. marginalis (previously recognized as Aurelia sp. 9; also see Table S4 597 and Figs. S5-S6). In our concatenated phylogeny (Fig. 9) however, as for the 16S and COI 598 single-marker phylogenies (Figs. S4-S5), this species fell in a separate clade from A. marginalis. 599 These two taxa considered as separate species should not come as a surprise, as previous studies 600 also demonstrated the occurrence of another sympatric species in the area, A. montyi sp. nov.

601 (recognized as Aurelia cf. sp. 2 in Chiaverano et al., 2016; described herein). For a brief 602 morphological description of the medusa stage see Table S8.

603

604

605

606

607

608

609

610

611

612

613

614

615

616

617

618

619

620

621

622

623

624

625

626

627

628

629

Aurelia marginalis Agassiz, 1862

Aurelia sp. 9 Dawson et al., 2005. Ki et al., 2008; Ramšak et al., 2012; Dong et al., 2015; He et al., 2015; Chiaverano et al., 2016; Scorrano et al., 2016; Chiaverano and Graham, 2017; Gómez-Daglio and Dawson, 2017; Abboud et al., 2018; Dong, 2018, Frolova and Miglietta, 2020.

Type material: Holotype: Medusa, MCZ 352.

Type locality: Key West, Florida, United States of America (Fig. 10).

Distribution: Across the Gulf of Mexico (Table S4).

Diagnosis: There were 20 diagnostic positions for COI and three for 28S (Table S6).

Remarks: Specimens of both previously recognized $A$. sp. 9 (here synonymized) and $A$. cf. sp. 2 lineages (herein described as $A$. montyi sp. nov.) have been collected in the Florida Keys (Long Key, Florida, USA), which is within the "reefs of Florida", locality cited in the description of Aurelia marginalis, and very near the type specimen's locality. Even though we portray in this study the unreliability of morphological data for species recognition (further discussed), we decided to synonymize A. sp. 9 under A. marginalis, as in this species' description, Agassiz (1862) mentions the distinct rose color of the gonads, which is also presented by Chiaverano et al. (2016) for $A$. sp. 9 when compared to $A$. cf. sp. 2 (A. montyi sp. nov.) (see Fig. 1 in Chiaverano et al., 2016). Nevertheless, this should not be used as diagnostic, as color has been previously reported on holding no value for systematics in this genus (Kramp, 1968), and even in other Medusozoa (Lampert et al., 2011; Holst and Laakmann, 2014).

A. marginalis was resurrected by Calder (2009), due to differences with specimens from the northeastern USA, which were reported as more similar to Aurelia aurita from northern Europe. These differences came mostly from polyps, on their free amino acid composition, nematocyst types, morphology, and asexual reproduction (Calder, 2009). The use of

630

631 morphological characters in polyps to recognize different Aurelia species has been reported as problematic (Gambill and Jarms, 2014), which was further corroborated by the possibility of

632 morphological plasticity due to environmental differences (Chiaverano and Graham, 2017). The

633 use of nematocyst types for species recognition can also be problematic (Francis, 2004; Acuña et

634

635 al., 2011). Therefore, we do not report these as diagnostic for this species, but we corroborate the resurrection by Calder (2009) with a molecular genetic diagnosis. Other synonyms for this 
636 species have been presented, but we refrain from maintaining them, as they could belong to other

637 species present in the Gulf of Mexico, and until now we could not confirm it. For a brief

638 morphological description of the polyp, ephyra and medusa stages see Table S8.

639

640 Aurelia montyi Lawley, Gamero-Mora, Maronna, Chiaverano, Stampar, Hopcroft, Collins and 641 Morandini sp. nov.

642

643

644

645

646

647

648

649

650

651

652

653

654

655

656

657

658

659

660

661

662

663

664

665

666

667

668

669

670

671

672

673

674

675

Aurelia cf. sp. 2 Chiaverano et al., 2016.

Type material: Holotype: Tissue (Medusa), USNM 1643581. Paratypes: Tissue (Medusa), USNM 1643582-1643583.

Type locality: Dauphin Island, Alabama, United States of America (Fig. 10).

Etymology: Named after Dr. William "Monty" Graham (University of Southern Mississipi, USA), who was a pioneer in ecological studies with Aurelia in the Gulf of Mexico and former advisor of LMC (co-author in this study), both of which collected and sequenced most of the specimens that belong to this species.

Distribution: Eastern Gulf of Mexico (Table S4).

Diagnosis: There were five diagnostic positions for 16S, 11 for COI and six for ITS1 (Table S6).

Remarks: This species was considered as $A$. cf. sp. 2 because it was in the same clade as A. sp. 2 (herein described as $A$. cebimarensis sp. nov.) in the ITS1 phylogeny (see Fig. 5 in Chiaverano et al., 2016), even though there were considerable branch lengths separating them and they were reciprocally monophyletic in the COI phylogeny (see Fig. 4 in Chiaverano et al., 2016). Nevertheless, by including more genetic data, all of the phylogenies that included this species returned it as a separate clade (Fig. 9; Figs. S4-S6), which seems enough evidence now to corroborate this species' hypothesis. For a brief morphological description of the medusa stage see Table S8.

Aurelia smithsoniana Lawley, Gamero-Mora, Maronna, Chiaverano, Stampar, Hopcroft, Collins and Morandini sp. nov.

Aurelia sp. 15 Gómez-Daglio and Dawson, 2017. Abboud et al., 2018; Dong, 2018.

Type material: Holotype: DNA extraction, MZUSP 8656.

Type locality: Bocatorito Bay, Bocas del Toro, Panama (Fig. 10).

Etymology: Named after the Smithsonian Tropical Research Institute, in Bocas del Toro, Panama, which has supported studies in marine science for decades, especially in the Bocas del Toro area, where this species is distributed.

Distribution: Bocas del Toro, Panama (Table S4).

Diagnosis: There were 10 diagnostic positions for $16 \mathrm{~S}$ and seven for COI (Table S6). 
676 Remarks: In our 28S phylogeny (Fig. S7), this species appears in a single clade with $A$. 677 cebimarensis sp. nov., although they appear reciprocally monophyletic in the 16S and COI 678 phylogenies (Figs. S4-S5), and more importantly in the concatenated phylogeny (Fig. 9).

679 Furthermore, even though there are reported cases of sympatric Aurelia species (Chiaverano et 680 al., 2016) and multiple introductions (Dawson et al., 2005), the disjunct distribution of these 681 sister species in neighboring but different biogeographic realms (Costello et al., 2017), as well as 682 different large marine ecosystems (Sherman, 1991), could be further evidence of lineage

683 separation. For a brief morphological description the medusa stage see Table S8.

684

Aurelia cebimarensis Lawley, Gamero-Mora, Maronna, Chiaverano, Stampar, Hopcroft, Collins and Morandini sp. nov.

687

688

689

690

691

692

693

694

695

696

697

698

699

700

701

702

703

704

705

706

707

708

709

710

711

712

713

Aurelia sp. 2 Dawson and Jacobs, 2001. Dawson, 2003; Dawson et al., 2005; Morandini et al., 2005; Ki et al., 2008; Bayha et al., 2010; Ramšak et al., 2012; Dong et al., 2015; He et al., 2015; Chiaverano et al., 2016; Scorrano et al., 2016; Goméz-Daglio and Dawson, 2017; Dong, 2018.

\section{Type material: Holotype: Medusa, MZUSP 8644. Paratypes: Medusa, MZUSP 8643;} Polyps, MZUSP 8646; Tissue (Ephyrae), MZUSP 8645.

Type locality: Pedra do Baleeiro at Praia do Cabelo Gordo, São Sebastião, São Paulo, Brazil (Fig. 10).

Etymology: Named after the Centro de Biologia Marinha (CEBIMar) of the University of São Paulo, situated exactly where the type specimen was collected. This center is an international reference in marine biology studies, and many of the authors in this study have depended heavily on these facilities for their education and research.

Distribution: Our records include specimens from across the São Paulo state and from Aracaju, Sergipe. Therefore, the distribution likely spans the Brazilian coast from southeast to northeast (Table S4). (Table S6).

Diagnosis: There were five diagnostic positions for $16 \mathrm{~S}$, four for COI and 16 for ITS1

714 culture as in their study, were recognized as a different species, Aurelia insularia sp. nov. (see 
715 also remarks in this species' description herein). For a brief morphological description of the

716 polyp, ephyra and medusa stages see Table S8.

717

718 Aurelia malayensis Lawley, Gamero-Mora, Maronna, Chiaverano, Stampar, Hopcroft, Collins

719

720

721

722

723 and Morandini sp. nov.

724

725

726

727

728

729

730

731

732

733

734

735

736

737

738

739

740

741

742

743

744

745

746

747

748

749

750

751

752

753

Aurelia sp. 4 Dawson and Jacobs, 2001. Dawson, 2003; Dawson et al., 2005; Ki et al., 2008; Ramšak et al., 2012; Bayha and Graham, 2014; Dong et al., 2015; He et al., 2015; Chang et al., 2016; Chiaverano et al., 2016; Scorrano et al., 2016; Dong et al., 2017; Abboud et al., 2018; Dong, 2018. 8651.

Type material: Holotype: Polyps, MZUSP 8650. Paratypes: Tissue (Polyps), MZUSP

Type locality: Palawan, Philippines (Fig. 10).

Etymology: Named after the Malay Archipelago, situated between mainland Indo-China and Australia, which includes the type locality and the suggested endemic distribution for this species (Dawson et al., 2005).

Distribution: Across the Malay Archipelago to southern Japan, as well as in Hawaii (Table S4).

Diagnosis: There were 20 diagnostic positions for $16 \mathrm{~S}, 17$ for COI, 18 for ITS1 and four for 28S (Table S6).

Remarks: This species has been hypothesized as endemic to eastern Borneo and Palau, with the possibility of natural dispersal across the Malay Archipelago, south to Australia and north to Japan (Dawson et al., 2005). Therefore, the occurrence in Hawaii would come from an anthropogenic introduction, likely after considerable WWII naval traffic (Dawson et al., 2005).

Previous studies have shown that even though there are genetic differences distinguishing Palau specimens from those of other localities, they have similar rates of feeding, growth, respiration and swimming, if compared to A. aurita from the Black Sea (Dawson and Martin, 2001). Also, morphological variation between populations within a species sometimes exceeded variation between species within the Palau region (Aurelia sp. 3, Aurelia sp. 4, herein described as A. malayensis sp. nov., and Aurelia sp. 6, herein synonymized under Aurelia clausa; Dawson, 2003), which makes morphological diagnosis unreliable, as we also present in this study (further discussed).

Mayer (1910) mentions the distribution of Aurelia colpota Brandt, 1835 across the IndoPacific. As the type specimen was described in South Africa and we cannot rely on morphology for further comparisons (further discussed), we refrain from resurrecting this name. Also, a COI sequence of a specimen from Palau, previously considered as $A$. sp. 4, was herein treated as $A$. cf. malayensis, as it appeared as sister taxa to the clade containing the remainder of the species' terminal taxa in both COI (Fig. S5) and concatenated phylogenies (Fig. 9; see Table S4 for 
754 details on this specimen's sequence). For a brief morphological description of the polyp, ephyra

755

756

757

758

759

760

761

762

763

764

765

766

767

768

769

770

771

772

773

774

775

776

777

778

779

780

781

782

783

784

785

786

787

788

789

790

791

792

793 and medusa stages see Table S8.

Aurelia clausa Lesson, 1830

Aurelia sp. 6 Dawson and Jacobs, 2001. Dawson, 2003; Dawson et al., 2005; Ki et al., 2008; Häussermann et al., 2009; Ramšak et al., 2012; Dong et al., 2015; He et al., 2015; Chang et al., 2016; Chiaverano et al., 2016; Scorrano et al., 2016; Abboud et al., 2018; Dong, 2018.

Type material: Based on our inquiries, no type material remains. Other material from the vicinity of the type locality (New Britain, Papua New Guinea) might remain in the private collection of Dawson et al. (2005), as they deposited a sequence from this locality in GenBank (Table S4).

Type locality: New Ireland, Papua New Guinea (Fig. 10).

Distribution: Palau lakes, Papua and Papua New Guinea (Table S4).

Diagnosis: There were 20 diagnostic positions for COI and 20 for ITS1 (Table S6).

Remarks: Some sequences from New Zealand posted in GenBank were identified as Aurelia aff. clausa (Table S4). However, A. clausa was described from New Ireland, Papua New Guinea, and a specimen that belongs to the previously considered $A$. sp. 6 lineage was collected from New Britain, Papua New Guinea, in the vicinity of the type locality. Therefore, specimens in this lineage are here synonymized under A. clausa. For more information on previous studies regarding ecology and morphology of this species see remarks for $A$. malayensis sp. nov. For a brief morphological description of the medusa stage see Table S8.

Aurelia dubia Vanhöffen, 1888

Aurelia ARAB lineage Schroth et al., 2002. Dawson, 2003; Dawson et al., 2005.

Type material: Based on our inquiries, no type material remains. Other material might remain in the private collection of Schroth et al. (2002), as they deposited the sequences for this species in GenBank (Table S4).

Type locality: Persian (Arabian) Gulf (Fig. 10).

Distribution: Arabian Peninsula, in the Red Sea and Persian Gulf (Table S4).

Diagnosis: There were eight diagnostic positions for 16S and 20 for ITS1 (Table S6).

Remarks: Schroth et al. (2002) defined the ARAB lineage with specimens from the Red Sea and from the Persian Gulf, the latter indicated as the type locality for Aurelia dubia.

Nevertheless, they only deposited two sequences from this lineage in GenBank, one for 16S and one for ITS1, the former without any specification of the collection locality and the latter from a Persian Gulf specimen. In our single-marker phylogenies, the ITS1 sequence appears separate from all other Aurelia (Fig. S6), while for $16 \mathrm{~S}$, it forms a clade with a specimen from the Red

PeerJ reviewing PDF | (2021:04:60391:1:0:NEW 8 Jul 2021) 
794 Sea (Fig. S4). Considering that the ARAB lineage was defined also based on samples from the

795

796

797

798

799

800

801

802

803

804

805

806

807

808

809

810

811

812

813

814

815

816

817

818

819

820

821

822

823

824

825

826

827

828

829

830

831

832

833

Red Sea, it is possible that these specimens belong to the same species. We herein resurrect $A$. dubia encompassing the distribution of the ARAB lineage (suggested previously in Dawson, 2003), although we identify the specimen from the Red Sea as A. cf. dubia, until more markers are sequenced or further samples are collected that can ensure the identity of this specimen within A. dubia. For a brief morphological description of the medusa stage see Table S8.

Aurelia solida Browne, 1905

Aurelia TET lineage Schroth et al., 2002.

Aurelia sp. 8 Dawson et al., 2005. Ramšak et al., 2012; Ki et al., 2008; Manzari et al., 2015; Dong et al., 2015; He et al., 2015; Marques et al., 2014; Chiaverano et al., 2016. Aurelia sp. Tinta et al., 2010 (Bay of Piran).

Type material: Holotype: Medusa, NHM 1948.10.1.239.

Type locality: Republic of Maldives (Fig. 10).

Distribution: Across the Mediterranean Sea and the Red Sea (Table S4).

Diagnosis: Absence of an endodermal ocellus on the subumbrellar side of rhopalia

(Scorrano et al., 2016; see remarks below). There were 10 diagnostic positions for 16S, 20 for COI, 20 for ITS 1 and three for 28S (Table S6).

Remarks: The recent redescription of this species established holotypes and paratypes (Scorrano et al., 2016), but a holotype was already available and therefore is here designated. Also, the locality where specimens were collected for redescription is not concordant with the type locality (Republic of Maldives), so resurrection of the name was based on the direction of the rhopalium, which pointed to the exumbrellar side $\left(90^{\circ}\right.$ angle) (Scorrano et al., 2016).

However, we also observed this in specimens from very distinct localities, such as the southwestern USA and the Atlantic Ocean off Portugal (Fig. 12A-D). Other observations herein have also indicated that morphology of rhopalia can vary even within species (Fig. 7B, D).

Nevertheless, the presence or absence of an endodermal ocellus in specimens that also had an angled rhopalium could not be verified, as they can fade with preservation. This character may also vary, but until further specimens are analyzed, it is maintained as diagnostic alongside the genetic diagnosis.

No sequences have been obtained from specimens of the Maldives to confirm the distribution of this species in this locality. Nevertheless, it has been hypothesized that this species was introduced from the Indian Ocean into the Mediterranean through the Suez Canal (Dawson et al., 2005; Scorrano et al., 2016). For a brief morphological description of the polyp, ephyra and medusa stages see Table S8.

Aurelia labiata Chamisso and Eysenhardt, 1821

PeerJ reviewing PDF | (2021:04:60391:1:0:NEW 8 Jul 2021) 
834

835

836

837

838

839

840

841

842

843

844

845

846

847

848

849

850

851

852

853

854

855

856

857

858

859

860

861

862

863

864

865

866

867

868

869

870

871

872

873

Type material: Neotype: Medusa, CASIZ 111024.

Type locality: Monterey Bay, California, United States of America (Fig. 10).

Distribution: Northern coast of California, USA, north to Canada and into Alaska, USA (Table S4).

Diagnosis: There were 13 diagnostic positions for COI (Table S6).

Remarks: In the COI phylogeny we were able to observe two distinct clades within what was previously considered as Aurelia labiata (Fig. S5). In the 16S and ITS1 single-marker phylogenies, due to less sampling or even to different evolutionary rates across markers, it was not possible to observe reciprocally monophyletic clades (Figs. S4, S6). However, five specimens, two within A. labiata and three within Aurelia columbia sp. nov. (herein described) clades in the COI phylogeny had one other sequenced marker (Table S4). These specimens were used for the concatenated phylogenetic analysis, which recovered the same reciprocal monophyly as for COI, as well as to tentatively identify 16S and ITS1 sequences that fell within the same monophyletic or paraphyletic group in these phylogenies (see A. cf. labiata and $A$. cf. columbia in Table S4).

In only one of the COI clades was there a specimen from California, USA (Fig. S5), where the type locality for A. labiata is situated, and is therefore included under this species' hypothesis. Also, additional preserved material in this species' redescription (Gershwin, 2001) is from Tomales Bay, California (CAS 111023), from where the Californian sequenced specimens included herein are. As the distribution of A. labiata overlaps with $A$. columbia sp. nov., we refrain from acknowledging any previous mentions as synonyms.

A distinct character included as diagnostic in both the original description and redescription of $A$. labiata, is the prominent manubrium (from the latin labium, meaning "lip"; for images and illustrations see Gershwin, 2001). This feature has been previously reported for other localities in the Pacific and Indian oceans, in specimens identified as A. labiata or even as Aurelia maldivensis Bigelow, 1904 (Mayer, 1910). We also made these observations in some of the preserved specimens from the western coast of the USA, the Atlantic Ocean off Portugal and even from other localities, such as Japan and the western coast of Panama (Fig. 13A-B; also see $\mathrm{f} 2$ in Tables S1-S2). Also, the number of marginal lobes (also called bell scalloping), considered previously as 16 for A. labiata and its variaties (Mayer, 1910), had already been disregarded as taxonomically significant in the species' redescription. This can be further emphasized in this study, as specimens from the Brazilian coast also seem to have more pronounced non-rhopaliar indentations (see f30 in Figs. 3-4), which defines the secondary scalloping.

None of the specimens sequenced from the western Pacific or Indian Oceans, which can present similar morphology to the previously considered $A$. labiata, clustered within any of the non-introduced northeastern Pacific species clades (which excludes A. coerulea). Until further studies can assess variability and plasticity of bell indentations and manubrium length, we refrain from using these characters in the diagnosis. For a brief morphological description of the polyp, ephyra and medusa stages see Table S8. 
874 Aurelia columbia Lawley, Gamero-Mora, Maronna, Chiaverano, Stampar, Hopcroft, Collins and 875 Morandini sp. nov.

876

877

878

879

880

881

882

883

884

885

Type material: Holotype: Polyps, UF 12778.

Type locality: San Juan Island, Washington, USA (Fig. 10).

Etymology: Named after British Columbia, where most of the sequenced specimens have been collected.

Distribution: Northwestern coast of the USA, north to Canada (Table S4).

Diagnosis: There were 16 diagnostic positions for COI (Table S6).

Remarks: This species is sympatric with A. labiata, which spans from California to Alaska (USA) in the northeastern Pacific (see remarks for A. labiata). Gershwin (2001), in the redescription of $A$. labiata, observed three morphotypes occurring in a latitudinal gradient. These

886 morphotypes may not be species-specific, as we here describe another species that occurs across the range of $A$. labiata. Further studies integrating molecular phylogenetics and morphometrics may unravel morphological variation and plasticity within these species. For a brief

889

890

891

892

893

894 morphological description of the polyp stage see Table S8.

Aurelia relicta Scorrano, Aglieri, Boero, Dawson and Piraino, 2016

897

898

899

900

901

902

903

904

905

906

907

908

909

910

Aurelia sp. Benovic et al., 2000. Malej et. al., 2007; Turk et al., 2008; Tinta et al., 2010 (Big Lake).

Aurelia sp. 5 Dawson and Jacobs, 2001. Dawson et al., 2005; Ki et al., 2008; D’Ambra and Graham, 2009; Malej et al., 2009; Kogovšek et al., 2012; Korsun et al., 2012; Ramšak et al., 2012; D’Ambra et al., 2013; Manzari et al., 2015; Wang and Sun, 2014; Chiaverano et al., 2015; Dong et al., 2015; He et al., 2015; Marques et al., 2014; Chiaverano et al., 2016; Miloslavić et al., 2016.

$$
\text { Aurelia MS-MKL Schroth et al., } 2002 .
$$

\section{Type material: Holotype: Medusa, UNIPD CN57CH. Paratypes: Medusa, UNIS_SCY_028/29.}

Type locality: Veliko Jezero, Mljet Island, Croatia (Fig. 10).

Distribution: Mljet Island lakes, Croatia (Table S4).

911 sequence from that specimen fell within a clade alongside the other sequences from the same

912 locality, within the A. aurita clade (Fig. S6), while the COI sequence from that same specimen

913 fell within the $A$. relicta clade (Fig. S5). This can potentially be due to contamination in 
914 sequencing the COI, as in the aforementioned study, A. relicta specimens from the Mljet lakes

915 were also being sequenced. As other sequences from both $A$. aurita and $A$. relicta were available,

916 this specimen from Ramšak et al. (2012) was disregarded from the concatenated phylogenetic

917 analysis in our study.

918 Scorrano et al. (2016) presented a table with diagnostic characters for some of the

919 Mediterranean species of Aurelia, from the polyp, ephyra and medusa stages. Nevertheless,

920 based on the unreliability of medusa morphometric features for species recognition shown herein

921 (further discussed); and the potential confusion that can arise from polyp and ephyra morphology

922 (Gambill and Jarms, 2014), especially considering the possibility of morphological plasticity in

923 these life cycle stages (Chiaverano and Graham, 2017), we refrain from including them here.

924 Furthermore, there seem to be no unambiguous categorical features, if compared to A. coerulea

925 and $A$. solida (see Table 2 in Scorrano et al., 2016, and remarks of these species in this study).

926 For a brief morphological description of the polyp, ephyra and medusa stages see Table S8.

927

928

Aurelia persea (Forskål, 1775)

929

930

931

932

933

934

935

936

937

938

939

940

941

942

943

Aurelia sp. Mizrahi, 2014.

944

945

Type material: Based on our inquiries, no type material remains. Other material from the type locality region might remain in the private collection of Mizrahi (2014), as he deposited sequences of a specimen from this locality in GenBank (Table S4).

Type locality: Mediterranean Sea (Fig. 10).

Distribution: Sequences of specimens herein included derive only from Haifa Bay, Israel (Table S4).

\section{(Table S6).}

Diagnosis: There were 13 diagnostic positions for 16S, 20 for COI and three for $28 \mathrm{~S}$

946

947

Remarks: The original description of this species is brief and simple, which therefore later rendered it as synonymous to A. aurita (Agassiz, 1862). Even if the description was more informative, there is only one image of the sequenced specimen (see Fig. 17 in Mizrahi, 2014), from which hardly any information can be retrieved. Furthermore, as we portray in this study the unreliability of medusa morphology for species identification (further discussed), we resurrect Aurelia persea because it is the oldest available name that encompasses the locality of the sequenced specimen treated herein. For a brief morphological description of the medusa stage

948

949 see Table S8.

Aurelia aurita (Linnaeus, 1758)

950

951 Aurelia BOR lineage Schroth et al., 2002.

952 Aurelia borealis Schroth et al., 2002.

953 
954

955

956

957

958

959

960

961

962

963

964

965

966

967

968

969

970

971

972

973

974

975

976

977

978

979

980

981

982

983

984

985

986

987

988

989

990

991

992

993

Type material: Neotype: Tissue (Medusa), MZUSP 8657.

Type locality: Helgoland, Germany (Fig. 10).

Distribution: North, Black, Baltic and Caspian Seas, Northeast Atlantic, Greenland, northeastern USA and Canada, Northwest Pacific and South America (Table S4).

Diagnosis: There were five diagnostic positions for 16S, 20 for COI, 20 for ITS1 and 12 for 28S (Table S6).

Remarks: In Ramšak et al. (2012), one of the specimens collected in the Mljet lakes, in Croatia, appeared as sister taxa to a specimen from the Southwest Atlantic in their combinedmarker phylogeny. In our single-marker phylogenies, we observed that the ITS1 sequence from that specimen fell within a clade alongside the other sequences from the same locality, within the Aurelia relicta clade (Fig. S6), while the COI sequence from that same specimen fell within the A. aurita clade (Fig. S5). This can be due to contamination in sequencing the COI, as in the aforementioned study, $A$. aurita specimens were also being sequenced. As other sequences from A. relicta were available, this specimen from Ramšak et al. (2012) was disregarded for the concatenated phylogenetic analysis herein.

Previously, many species of Aurelia were synonymized under A. aurita (originally described from the Baltic Sea), as no morphological distinction could be made, and this species was considered globally distributed (Kramp, 1965, 1968; Russell, 1970; Larson, 1990; Arai, 1997). More recently, it has been recognized that, alongside A. coerulea, this species has one the widest distributions in the genus, but possibly due to multiple introductions from its endemic range in the Northeast Atlantic (potentially naturally dispersed to northeastern USA, although not so likely; see Dawson et al., 2005). Only one specimen of $A$. aurita is from the Northwest Pacific, reported from Armani et al. (2013), from a northwestern Pacific sample that is also present in Schroth et al. (2002). This could represent a new point of introduction of this species, and should be confirmed in the future with further collections in the area. Also, we recorded this species for the first time in Ushuaia, Argentina (Table S4), which could represent a new point of introduction but also ongoing spread from a single introduction that has been recorded in other localities along that region of South America (Häussermann et al., 2009). Other synonyms for this species have been presented, but we refrain from maintaining them, as they could belong to other species and until now we could not confirm it. For a brief morphological description of the polyp, ephyra and medusa stages see Table S8.

\section{Aurelia coerulea von Lendenfeld, 1884}

Aurelia japonica Kishinouye, 1891.

Aurelia sp. 1 Dawson and Jacobs, 2001. Dawson, 2003; Dawson et al., 2005; Ki et al., 2008; Häussermann et al., 2009; Ramšak et al., 2012; Wang and Sun, 2014; Dong et al., 2015; He et al., 2015; Marques et al., 2014; Chiaverano et al., 2016; Dong et al., 2017.

Aurelia UBI lineage Schroth et al., 2002.

Aurelia sp. Manzari et al., 2015. 
994

995

996

997

998

999

1000

1001

1002

1003

1004

1005

1006

1007

1008

1009

1010

1011

1012

1013

1014

1015

1016

1017

1018

1019

1020

1021

1022

1023

1024

1025

1026

1027

1028

1029

1030

1031

1032

1033

Type material: Holotype: NHM 1886.7.8.6.

Type locality: Port Jackson, Sydney, Australia (Fig. 10).

Distribution: Northwestern Pacific, Australia, west coast of the USA, Mediterranean and Atlantic coast of Europe (Table S4).

Diagnosis: There were 15 diagnostic positions for 16S, 20 for COI, 18 for ITS 1 and one for 28S (Table S6).

Remarks: The recent redescription of this species established holotypes and paratypes (Scorrano et al., 2016), but a holotype was already available and therefore is here designated. Interestingly, the type locality is not concordant with the inferred biogeographic origin in the coastal waters of the Western Pacific (Dawson et al., 2005). This species has one of the broadest distributions in the genus, with multiple introductions across the globe (Dawson et al., 2005). Anecdotal observations of polyps in cultivation in different temperatures $\left(15-24^{\circ} \mathrm{C}\right)$, suggest that they strobilate more frequently than other Aurelia species, even though under the exact same conditions. This could enhance its potential for spread, a matter for future studies to test.

A potential distinct feature in this species is the dark-orange or brownish color of the recently released ephyrae, which is appointed as diagnostic (Scorrano et al., 2016) and that we have also observed in our lab cultures. However, until a further assessment of ephyrae coloration in more Aurelia species is undertaken, and due to past reports of the unreliability of coloration for species identification in this genus (Kramp, 1968) and in other Medusozoa (Lampert et al., 2011; Holst and Laakmann, 2014), we abstain from including this as diagnostic. Further characters also indicated as diagnostic for polyps and ephyrae can derive from morphological variability, which has been noticed in this species (Scorrano et al., 2016) and also in other species of the genus (Gambill and Jarms, 2014; Chiaverano and Graham, 2017). For more information on morphological variability in medusae of this species see section 'Morphological variability and diagnosis in Aurelia coerulea'. For a brief morphological description of the polyp, ephyra and medusa stages see Table S8.

\section{Aurelia limbata Brandt, 1835}

\section{Type material: Neotype: Polyps, MZUSP 8660. Paraneotype: Tissue (Polyps), MZUSP 8661.}

Type locality: Okirai Bay, Ofunato, Japan (Fig. 10).

Distribution: Northwestern Pacific (Table S4).

Diagnosis: There were three diagnostic positions for 16S, 20 for COI, 19 for ITS1 and six for 28S (Table S6).

Remarks: Brandt (1835) described this species of Aurelia from the northwestern Pacific (Avacha Bay, Kamchatka, Russia) as very distinct due to the dark-brownish color of its bell margin and the brown or yellowish coloration of radial canals, which were highly ramified. This is clearly represented in the illustration in his next publication (Brandt, 1838). This 
1034 morphological pattern is also associated to records in the northeastern Pacific, including the 1035 cover photograph of the January 1974 issue of Audubon magazine, featuring a specimen from

1036 the Aleutian Islands (Larson, 1990; Gershwin, 2001). However, more recent accounts, including 1037 the sequences herein, are only from the northwestern Pacific (Miyake et al., 2002; Chang et al., 1038 2016).

1039 There are other Aurelia species that occur in the northeastern Pacific, in Alaska, USA, 1040 such as Aurelia hyalina and A. labiata, the former even previously identified as A. limbata (see 1041 remarks for A. hyalina in this study). Gershwin (2001) even suggested that $A$. limbata could be a 1042 color morph, part of the A. labiata species complex. Whether the distribution of $A$. limbata 1043 actually extends across the North Pacific or the distinct coloration is not intraspecific, is still 1044 unclear. Considering this controversy and previous accounts on the unreliability of coloration for 1045 species recognition in this genus (Kramp, 1968) and in other Medusozoa (Lampert et al., 2011; Holst and Laakmann, 2014), we refrain from including this as diagnostic.

Regarding the highly ramified radial canals in the original description (Brandt, 1835), we observed the highest number of branching points in specimens from Japan and Arctic Alaska, USA (black squares in Figs. 3-4; Fig. 6C). This is concordant with the distribution of sequenced specimens of A. limbata (Japan) and A. hyalina (Arctic). Therefore, as discussed previously for coloration, the ramification pattern of radial canals might not be intraspecific, and once more we refrain from including this in the diagnosis. This follows the conclusions of this study, that shows the unreliability of morphology for species recognition due to morphological variability (further discussed), and we present a molecular genetic diagnosis to support this species hypothesis.

In this potential confusion regarding distribution and morphology of A. limbata and $A$. hyalina, we abstain from reporting previous accounts as synonyms. Even with more recent studies that use molecular data, such as Schroth et al. (2002), there might be some issues. The $16 \mathrm{~S}$ sequence these authors posted in GenBank from the LIM lineage, which they consider $A$. limbata, belongs to the Mljet lakes, Croatia, and therefore in our 16S phylogeny is part of the $A$. relicta clade (Fig. S4). Another issue is the LIM lineage ITS1 sequence posted in GenBank, which if submitted to NCBI's BLAST returns Cyanea capillata (Linnaeus, 1758) as the most similar taxon, the chosen outgroup in that study. These issues are not uncommon, and can derive from contamination or even sample mislabeling. Still, within the LIM lineage there are specimens from Iceland, but they were not deposited in GenBank, and therefore we cannot confirm their identity to the species clades treated herein, likely either A. limbata or A. hyalina. For a brief morphological description of the polyp, ephyra and medusa stages see Table S8.

1070

Aurelia hyalina Brandt, 1835

1073

Aurelia limbata Dawson and Jacobs, 2001.

Aurelia sp. 10 Dawson et al., 2005. Ki et al., 2008; Häussermann et al., 2009; Ramšak et al., 2012; Dong et al., 2015; He et al., 2015; Scorrano et al., 2016; Dong, 2018. 
1074

1075

1076

1077

1078

1079

1080

1081

1082

1083

1084

1085

1086

1087

1088

1089

1090

1091

1092

1093

1094

1095

1096

1097

1098

1099

1100

1101

1102

1103

1104

1105

1106

1107

1108

1109

1110

1111

1112

1113

Type material: Neotype: Tissue (Medusa), USNM 1643575. Paraneotypes: Tissue (Medusa), USNM 1643579-1643580.

Type locality: Chukchi Sea, Russia (Fig. 10).

Distribution: Northeastern Russia, southwestern Alaska (USA), northeastern Canada and Greenland (Table S4).

Diagnosis: There were 12 diagnostic positions for COI and 19 for ITS1 (Table S6).

Remarks: In our 16S single-marker phylogeny this species appeared as a paraphyletic group (Fig. S4), although in the COI, ITS1 (Figs. S5-S6) and, more importantly, the concatenated phylogenies (Fig. 9), A. hyalina appears as monophyletic and sister to A. limbata.

We resurrect this name based on the neighboring distribution of the previous type locality (Aleutian Islands, Alaska, USA) with one of the sequenced specimens herein studied. This specimen was once considered to belong to A. limbata (Dawson and Jacobs, 2001), but later delimited as another species once other sequences from Japan and South Korea were added, which derived from specimens that fit within the original description of $A$. limbata (Dawson et al., 2005; Chang et al., 2016; also see remarks for A. limbata in this study). For a brief morphological description of the medusa stage see Table S8.

\section{Undescribed species and other currently valid names}

Most of the species hypotheses in this study that remain undescribed had been previously noted and in some cases delimited, such as $A$. sp. 3 (Dawson and Jacobs, 2001), Aurelia sp. 7 (Dawson et al., 2005), A. sp. 12, A. sp. 13, A. sp. 14 (Gómez-Daglio and Dawson, 2017) and Aurelia sp. 18 (as Aurelia sp. new., Frolova and Miglietta, 2020). In the case of Aurelia sp. 17 from the western coast of Thailand, Ruijuan et al. (2016) identified it as Aurelia sp., as in their 18S phylogeny these specimens were in the same clade as an A. coerulea specimen (as Aurelia sp. EU276014), but in their $16 \mathrm{~S}$ phylogeny, similar to the $16 \mathrm{~S}$ (Fig. S4) and concatenated phylogenies presented herein (Fig. 9), it appears in a distinct clade.

In the most recent accounts of Aurelia species, three other names are currently valid that were not detected in this study (A. colpota, A. maldivensis and Aurelia vitiana Agassiz and Mayer, 1899; Jarms and Morandini, 2019; Collins et al., 2020). In these recent accounts, $A$. dubia was synonymized under $A$. colpota, but as sequenced specimens studied herein closely matched the type locality of $A$. dubia, we prioritise the resurrection of this epithet (see remarks for $A$. dubia). For A. maldivensis and A. vitiana, described from the Maldives and Fiji respectively, none of the distributions of the undescribed species hypotheses overlapped or were near their type localities, and we therefore avoided any synonymization. We recommend that each of these three names are treated as species inquirenda, pending further investigation. A summary of the taxonomic history of Aurelia species treated herein is provided in Fig. 14, showing studies that either described or delimited one of these species for the first time and what other species were mentioned, including what names were used.

Peerj reviewing PDF | (2021:04:60391:1:0:NEW 8 Jul 2021) 


\section{Discussion}

\section{Variability and the use of morphology to diagnose}

1116 Most descriptions of Aurelia species were based on the medusa stage, which is the most

1117 conspicuous and easily collected of the life cycle stages (Mayer, 1910 reviews morphology of

1118 Aurelia species and their varieties that had been described). Overlaps in morphological

1119 differences across large spatial scales created much confusion for species identification, until the

1120 incorporation of molecular genetic data propelled a re-evaluation of morphological characters in

1121 all life cycle stages (Dawson and Jacobs, 2001; Schroth et al., 2002; Dawson, 2003; Dawson et

1122 al., 2005; Gambill and Jarms, 2014). Recent descriptions of species hypotheses based on genetic

1123 data acknowledge some morphological features of medusae as diagnostic (Scorrano et al., 2016).

1124 In our evaluation of Aurelia specimens from across the globe, we found no geographic

1125 organization associated with morphological variation. On the contrary, morphological variation

1126 among specimens within regions, and even within collection lots, usually overlapped with that of

1127 specimens from very distinct localities (Figs. 3-4). If, however, neighboring regions had

1128 structured morphological dissimilarities, this could mean that morphotypes might be

1129 distinguished in smaller spatial scales, and if related to species hypotheses, these could be useful

1130 to distinguish neighbor or even sympatric species (e.g., Aurelia in the Gulf of Mexico, as in

1131 Chiaverano et al., 2016). We did not observe this pattern, but the opposite, that specimens

1132 distributed closer to each other tended to be more similar, although this was presented as either a

1133 weak or non-significant relationship. The morphological variation discussed above also

1134 encompassed previously considered categorical features, which could not be unambiguously

1135 determined, likely due to the higher sampling effort of this study, and were either removed from

1136 analyses or adapted to continuous or meristic features (such as f34-36 reflecting continuous

1137 variation from previously used f8; Table S3).

1138 The comparison of cultured Aurelia coerulea medusae with the species diagnosis,

1139 provided by specimens studied in the Mediterranean (Scorrano et al., 2016), further illustrates

1140 the potential for morphological variability, in both continuous and categorical features

1141 (illustrated in Fig. 7). Interestingly, the only specimens analyzed that were more morphologically

1142 similar to each other were from the cultures at the Discovery Place Aquarium (DP-Aq in Figs. 3-

1143 4; identified as A. coerulea based on genetic data, see Table S4). These were raised under

1144 roughly the same controlled conditions, such as temperature, water circulation, light intensity,

1145 and fed the same amount at the same time. Controlled conditions that reflect a certain

1146 morphological pattern corroborates the hypothesis for environmentally determined

1147 morphological plasticity, which has already been demonstrated for medusae of an Aurelia

1148 species in the field (Chiaverano et al., 2016). All of the evidence mentioned above favors the

1149 argument that medusa morphology is likely uninformative for species diagnosis in this genus.

1150 To further complicate matters, there are hypothesized multiple introductions of Aurelia

1151 species across the globe (Dawson et al., 2005; see examples in the remarks for $A$. coerulea,

1152 Aurelia aurita and Aurelia solida), and likely more still undetected. Even if species within

1153 neighboring regions could be distinguished by morphology, introduced species could confuse 
1154 these distinctions. This could also have confused our morphological analysis, as it is based on the 1155 geographic distribution of morphological dissimilarities that, in most cases, did not have direct

1156 equivalence to the genetic dataset, in which species hypotheses were based. Still, even

1157 considering potential confusions from that scenario, by relating the determined geographic

1158 regions with sampling sites of species hypotheses from genetic markers, no structure appears

1159 from morphological data (e.g., Japan and USA-SW, which could both belong to A. coerulea, see

1160 Figs. 3-4).

1161 However uninformative medusa morphology may be for species distinction, it is

1162 interesting to ponder the characters that account for most of the morphological variation across

1163 specimens, such as the branching pattern of radial canals and bell indentations, the latter which

1164 determines the number of lobes (scallops) on the umbrella margin. These characters were some

1165 of those previously used to recognize a few species: Aurelia labiata and Aurelia limbata were

1166 distinguished by the possession of 16 marginal scallops, while A. aurita only had eight (Mayer,

1167 1910; Gershwin, 2001); A. limbata was also reported to have highly branched radial canals in

1168 comparison to other species (Mayer, 1910; Gershwin, 2001). As more specimens were collected

1169 through time, these distinctions started to fade, and are further discussed for each species, when

1170 applicable, in the remarks of their systematic account in this study. Only one character from the

1171 medusa stage was maintained as potentially diagnostic, the absence of the endodermal ocellus in

1172 the rhopalia of $A$. solida (Scorrano et al., 2016). This character is usually faded in preserved

1173 material, and we could not observe it in the museum specimens analyzed.

1174 Other candidates as diagnostic morphological characters derive from other stages of the

1175 life cycle, such as polyps and ephyrae (Gambill and Jarms, 2014; Scorrano et al., 2016), which

1176 were not the focus of the morphological assessment herein presented. Nevertheless, previous

1177 studies have compared them in Aurelia, and have shown the overlap in morphology of these

1178 stages in different hypothetical species (Gambill and Jarms, 2014), as well as morphological

1179 plasticity in different sets of controlled conditions (Chiaverano and Graham, 2017), in line with

1180 the overall patterns discussed here for the medusa stage. Only one morphological character was

1181 here maintained as potentially diagnostic, the higher number of tentacles in polyps of Aurelia

1182 insularia sp. nov. (as Aurelia sp. 2 from Gambill and Jarms, 2014), until further studies can re-

1183 address this more thoroughly across the recently recognized diversity. Further discussions on the

1184 morphology of polyps and ephyrae, when applicable, are present in the remarks of each species'

1185 description.

1186

1187 Species delimitation, cryptic diversity and the transition to species description

1188 Acknowledging that morphology may not be informative for taxonomy, at least for some groups

1189 of metazoans, can be daunting. Morphology has been the basis of taxonomy for centuries,

1190 although the increase in accessibility to genetic data has raised doubts (Dayrat, 2005). Many

1191 studies that embrace this new source of information have revealed a previously undetected

1192 diversity, mostly named as 'cryptic' (for a review see Bickford et al., 2007). In result, it has been

1193 suggested that molecular data could be the only solution to assess the planet's biodiversity in the 
1194 midst of the extinction of both species and taxonomists (Hebert et al., 2003). Even though there

1195 is little consensus in that view (made clear by the reviews and comments in Goldstein and

1196 DeSalle, 2011, Collins and Cruickshank, 2013 and DeSalle and Goldstein, 2019), few studies

1197 have accepted the challenge of reconciling species delimitation and description for medusozoans,

1198 thus failing to provide both the scientific community and society of this taxonomic service

1199 (Jörger and Schrödl, 2013).

$1200 \quad$ Prior to descriptions, we assessed the use of molecular genetic markers herein studied as

1201 barcodes, in the sense of a potential tool for rapid identification. COI remains as the best

1202 candidate (as previously suggested for most metazoans, as well as medusozoans; Hebert et al.,

1203 2003; Ortman et al., 2010), as there is a greater gap between most intra- and interspecific

1204 distances (Fig. 11). However, some of the hypothesized species have between $6.2 \%$ and $9.8 \%$ of

1205 differences between them, and in the case of the sister species Aurelia smithsoniana sp. nov. and

1206 Aurelia cebimarensis sp. nov. it was as low as 2\% (Fig. 11; Table S7). As evolutionary rates may

1207 vary across congeners, it is hard to set a threshold for species identification, and this gap could

1208 be partly an artifact of unknown diversity due to undersampling (Meyer and Pauly, 2005;

1209 Wiemer and Fiedler, 2007; see Gómez-Daglio and Dawson, 2017 for other examples in

1210 medusozoans). Also, species hypotheses may change with future studies, and this gap could

1211 become more or less pronounced depending on what species hypotheses are accepted and

1212 considered. This may be a useful tool for first assessments and the discovery of potentially

1213 cryptic species, but it might not be reliable for species identification. Even less so should it be

1214 used for species delimitation, as neo-phenetic arbitrary constructs should not replace testable

1215 species hypotheses (Prendini, 2005; Valdecasas et al., 2008; see more in the 'Materials and

1216 Methods' section). For quite some time now the scientific community has accepted that

1217 similarity does not necessarily reflect kinship (i.e., evolutionary relationship), one of the basic

1218 principles of phylogenetic systematics (Hennig, 1966), which remains a key component for

1219 molecular species delimitation and taxonomy (Gómez-Daglio and Dawson, 2017).

With the results from past studies and those provided herein, we demonstrate that morphology is likely uninformative for distinguishing at least most of the species of the Aurelia genus. Even though some characters might yet be revealed as useful, and as we are only

1223 beginning to understand morphological variability and diversity within the genus, providing

1224 formal descriptions with a character-based diagnosis seems paramount to develop a taxonomic

1225 foundation for future studies. Character-based diagnosis, molecular or not, provides a falsifiable

1226 and comparable basis in which to build species hypotheses and descriptions (Grant et al., 2006;

1227 Bauer et al., 2011) and is required by the ICZN (1999; Article 13.1.1.). Also required to

1228 accompany newly described species are name-bearing types (ICZN, 1999; Article 72.3). Ideally,

1229 the type material that accompanies newly described species should be a specimen, from which a

1230 subsample is taken and DNA is extracted. For some samples in this study that was not possible,

1231 so to comply with the ICZN, the type material is provided as tissues or DNA extractions, and

1232 further specimens from the same culture or collection (when no sympatry had been recorded),

1233 when available, were provided within the type series (for other examples of species descriptions

PeerJ reviewing PDF | (2021:04:60391:1:0:NEW 8 Jul 2021) 
1234 with molecular genetic diagnosis and tissues or DNA extractions as type material, see Jörger and

1235 Schrodl, 2013; Eitel et al., 2018).

1236 Diagnostic molecular genetic characters have been identified as, for example, character

1237 attributes from sequence alignments, with sequences manually identified in groups of previously

1238 determined species hypotheses (Sarkar et al., 2008; as in Jörger and Schrödl, 2013), or as

1239 synapomorphies for the species clades observed in a phylogenetic tree (Machado, 2015; Eitel et

1240 al., 2018). We reported diagnostic characters as synapomorphies (sensu Grant and Kluge, 2004),

1241 as these rely directly on a phylogenetic inference and are portrayed in categories defined based

1242 on all possible optimization schemes for character-states (output from the program YBYRÁ;

1243 Machado, 2015). As a result, synapomorphies can be classified as ambiguously or

1244 unambiguously optimized, the latter which is further categorized into unique and non-

1245 homoplastic, unique and homoplastic or non-unique and homoplastic (Machado, 2015). The

1246 desired scenario regarding these categories would be to have unique and non-homoplastic

1247 synapomorphies (in black, Fig. 9 and Table S6) for each species hypothesis. With only five

1248 possible character-states (gaps as fifth state), it is not surprising that many species did not present

1249

1250

1251 these synapomorphies, mostly for COI, which is likely related to the much greater number of sequences in this dataset but could also be associated with varying evolutionary rates across markers. In that sense, the combination of synapomorphies as diagnostic, regardless of the

1252 category, could be more reliable.

1253 There seems to be great potential in synapomorphies not only to construct species

1254 hypotheses and provide descriptions, but also for species identification. A synapomorphy-based

1255 identification can be much more reliable than conventional barcoding or NCBI's BLAST, as it is

1256 not based on similarity but on specified characters that directly reflect species hypotheses. This

1257 has been somewhat attempted with CAOS's P-Elf program (Sarkar et al., 2008), but to our

1258 knowledge, none of the authors that report diagnostic characters from this program, such as

1259 Jörger and Schrödl (2013) and Maggioni et al. (2017), provided the output of the program's P-

1260 Gnome module, which would be used for classifying new sequences. These authors have

1261 otherwise suggested that diagnostic synapomorphy positions from the alignment, retrieved from

1262 CAOS, should be mapped to a reference sequence and both positions reported in the description.

1263 Yet, if other researchers seek to manually map their newly acquired sequences with any of the

1264 suggested above, for species identification, insertions and deletions could highly confuse the

1265 process, especially in genetic markers that commonly present them, such as those from

1266 ribosomal RNA regions (e.g., 16S, ITS1 and 28S). Furthermore, the algorithm used by P-Elf to

1267 classify new sequences is not clearly stated (Sarkar et al., 2008). A prospect for future studies

1268 would be to better evaluate and understand the possible issues involved in synapomorphy-based

1269 identifications and how to convert them in a computational pipeline that can be easily and widely

1270 used, such as the BLAST tool.

1271

1272 Conclusions 
1273 Our conclusion with this study is not that morphology should be left aside. On the

1274 contrary, we are just beginning to unravel how morphological variation can be environmentally

1275 induced (Chiaverano and Graham, 2017), as well as the evolutionary processes involved in

1276 morphological change and speciation (see Struck et al., 2017). For example, the morphological

1277 overlap we observed across species could be related to recent divergences, parallelism,

1278 convergence or even stasis, and most of these have already been demonstrated to occur in other

1279 medusozoans (Swift et al., 2016). A starting point for such studies in the jellyfish genus Aurelia

1280 could be investigating the characters that accounted for most of the morphological variation

1281 detected herein, such as bell indentations and ramification of radial canals, on more fine spatial

1282 scales considering environmental variation. This next step is fundamental to understand

1283 mechanisms that generated biodiversity and how these could be impacted by future changes.

1284

1285 Acknowledgements

1286 We thank institutions and associated staff that kindly provided us with preserved specimens for

1287 this study, such as Dr. Adam Baldinger (MCZ), Dr. John Slapcinsky (FLMNH), Dr. Eric Lazo-

1288 Wasem and Dr. Lourdes Rojas (YPM), Dr. Laura Pavesi (ZMUC), Prof. Elizabeth Neves

1289 (UFBA/MZUFBA), Dr. Aline Benetti (MZUSP), and Jorge Thé de Araújo (UFC). Also, a

1290 special appreciation to the Smithsonian Institution and the Invertebrate Zoology Department

1291 staff, William Geoff Keel, William Moser, Courtney Wickel, Chad Walter, Freya Goetz, Dr.

1292 Abigail Reft and Linda Cole, for providing not only specimens but support for analyzing most of

1293 them. Also, the aquariums and their staff that contributed with live material, Matt Wade (NA)

1294 and Matt Lowder (DP), as well as Dr. Jason Macrander and the Reitzel lab at University of North

1295 Carolina Charlotte (UNCC) for kindly assisting with the visit to DP. Molecular analyses were

1296 made possible by the Laboratory of Molecular Evolution at the University of São Paulo and their

1297 staff Manuel Antunes Jr., Beatriz V. Freire and Dr. Sabrina Baroni. Prof. Sérgio Tadeu helped

1298 with insights in the multivariate statistical analyses. We also thank Prof. Michael N. Dawson for

1299 comments on the first version of this manuscript, as well as the editor and three reviewers for

1300 suggestions on improvements prior to publication.

1301

1302 References

1303

1304

1305

1306

1307

1308

1309

1310

Abboud, S.S., Gómez-Daglio, L., Dawson, M.N., 2018, A global estimate of genetic and geographic differentiation in macromedusae - implications for identifying the causes of jellyfish blooms. Mar Ecol Prog Ser, 591, 199-216. http://doi.org/10.3354/meps12521

Acuña, F.H., Ricci, L., Excoffon, A.C., 2011. Statistical relationships of cnidocyst sizes in the sea anemone Oulactis muscosa (Actiniaria: Actiniidae). Belg J Zool, 141, 32-37.

Agassiz, L., 1862. Contributions to the natural history of the United States of America. Little Brown, Boston, 4, 1-380. http://doi.org/10.5962/bhl.title.12644

1311 http://doi.org/10.1007/978-94-009-1497-1 
1312 Agassiz, A., Mayer, A.G., 1899. Acalephs from the Fiji Islands. Bulletin of the Museum

1313 of Comparative Zoology of Harvard College, 32, 157-189.

1314 https://www.biodiversitylibrary.org/page/28879983

1315 Ames, C.L., Ohdera, A.H., Colston, S.M., Collins, A.G., Fitt, W.K., Morandini, A.C.,

1316 Erickson, J.S., Vora, G.J., 2021. Fieldable environmental DNA sequencing to assess jellyfish

1317 biodiversity in nearshore waters of the Florida Keys, United States. Front Mar Sci 8, 369.

1318 https://doi.org/10.3389/fmars.2021.640527

1319 Armani, A., Tinacci, L., Giusti, A., Castigliego, L., Gianfaldoni, D., Guidi, A., 2013.

1320 What is inside the jar? Forensically informative nucleotide sequencing (FINS) of a short

1321 mitochondrial COI gene fragment reveals a high percentage of mislabeling in jellyfish food

1322 products. Food Res Int, 54, 1383-1393. http://doi.org/10.1016/j.foodres.2013.10.003

1323 Bauer, A.M., Parham, J.F., Brown, R.M., Stuart, B.L., Grismer, L., Papenfuss, T.J.,

1324 Böhme, W., Savage, J.M., Carranza, S., Grismer, J.L., Wagner, P., Schmitz, A., Ananjeva, N.B.,

1325 Inger, R.F., 2011. Availability of new Bayesian-delimited gecko names and the importance of

1326 character-based species descriptions. P Roy Soc B-Biol Sci, 278, 490-492.

1327 http://doi.org/10.1098/rspb.2010.1330

1328 Bayha, K.M., Dawson, M.N., Collins, A.G., Barbeitos, M.S., Haddock, S.H.D., 2010.

1329 Evolutionary relationships among scyphozoan jellyfish families based on complete taxon

1330 sampling and phylogenetic analyses of $18 \mathrm{~S}$ and 28S ribosomal DNA. Integr Comp Biol, 50 ,

1331 436-455. http://doi.org/10.1093/icb/icq074

1332 Bayha, K.M., Graham W.M., 2014. Nonindigenous marine jellyfish: invasiveness,

1333 invisibility, and impacts, in: Pitt, K.A., Lucas, C.H. (Eds.), Jellyfish Blooms. Springer,

1334 Dordrecht, pp. 45-77. http://doi.org/10.1007/978-94-007-7015-7 3

1335 Benovic, A., Lucic, D., Onofri, V., Pehardia, M., Caric, M., Jasprica, N., Bobanovic-

1336 Colic, S., 2000. Ecological characteristics of the Mljet Islands seawater lakes (South Adriatic

1337 Sea) with special reference to their resident populations of medusae. Sci Mar, 64, 197-206.

1338 http://doi.org/10.3989/scimar.2000.64s1197

1339 Bickford, D., Lohman, D.J., Sodhi, N.S., Ng, P.K.L., Meier, R., Winker, K., Ingram,

1340 K.K., Das, I., 2007. Cryptic species as a window on diversity and conservation. Trends Ecol

1341 Evol, 22, 148-155. http://doi.org/10.1016/j.tree.2006.11.004

1342 Bigelow, H.B., 1904. Medusae from the Maldive Islands. Bulletin of the Museum of

1343 Comparative Zoology at Harvard College, 39, 245-269.

1344 https://www.biodiversitylibrary.org/page/4199303

1345 Brandt, J.F., 1835. Prodromus descriptionis animalium ab H. Mertensio in orbis terrarum

1346 circumnavigatione observatorum. Fascic. I. Polypos, Acalephas Discophoras et Siphonophoras,

1347 nec non Echinodermata continens. Sumptibus Academiae, Petropoli.

1348 http://doi.org/10.5962/bhl.title.10196

1349 Brandt, J.F., 1838. Ausführliche Beschreibung der von C.H. Mertens auf seiner

1350 Weltumsegelung beobachteten Schirmquallen, nebst allgemeinen Bemerkungen über die 
1351 Schirmquallen überhaupt. Mém l'Acad Impér Sci Saint-Pétersb, 6 Série, Sciences Naturelles, 2,

1352 237-411. http://biodiversitylibrary.org/page/29058927

1353 Bremer, K., 1994. Branch support and tree stability. Cladistics, 10, 295-304.

1354 http://doi.org/10.1111/j.1096-0031.1994.tb00179.x

1355 Browne, E.T., 1905. Scyphomedusae, in: Gardiner, J.S. (Ed.), The fauna and geography

1356 of the Maldive and Laccadive archipelagoes. Cambridge University Press, 2, pp. 958-971.

1357 Calder, D.R., 2009. Cubozoan and scyphozoan jellyfishes of the Carolinian

1358 Biogeographic Province, southeastern USA. Roy Ont Mus Contrib Sci 3: 1-58.

1359 Chamisso, A. de, Eysenhardt, C.G., 1821. De animalibus quibusdam e classe vermium

1360 linneana, in circumnavigatione terrae, auspicante Comite N. Romanzoff, duce Ottone de

1361 Kotzebue, annis 1815-1818. Fasciculus secundus, reliquos vermes continens. Nova Acta

1362 Physico-Medica Academiae Caesareae Leopoldino-Carolinae, Naturae Curiosorum, 10, 343-374.

1363 http://biodiversitylibrary.org/page/37020829

1364 Chang, S., Kim, J.N., Yoon, W., Ki, J., 2016. First Record of Two Cold-Water Jellyfishes

1365 Aurelia limbata and Parumbrosa polylobata (Scyphozoa: Semaeostomeae: Ulmaridae) in

1366 Korean Coastal Waters. Anim Syst Evol Divers, 32, 272-280.

1367 http://doi.org/10.5635/ASED.2016.32.4.037

1368 Chiaverano, L.M., Graham, W.M., Costello, J.H., 2015. Parasites alter behavior,

1369 reproductive output, and growth patterns of Aurelia medusae in a marine lake. Mar Ecol Prog

1370 Ser, 540, 87-98. http://doi.org/10.3354/meps11513

1371 Chiaverano, L.M., Bayha, K.M., Graham, W.M., 2016. Local versus generalized

1372 phenotypes in two sympatric Aurelia species: Understanding jellyfish ecology using genetics and

1373 morphometrics. Plos one, 11(6), e0156588, 1-24. http://doi.org/10.1371/journal.pone.0162118

1374 Chiaverano, L.M., Graham, W.M., 2017. Morphological plasticity in Aurelia polyps, with

1375 subsequent effects on asexual fecundity and morphology of young medusae. Mar Ecol Prog Ser,

1376 582, 79-92. http://doi.org/10.3354/meps12314

1377 Collins, A.G., Jarms, G., Morandini, A.C., 2020. World list of Scyphozoa. Aurelia

1378 Lamarck, 1816. Acessed through: World Register of Marine Species at:

1379 http://www.marinespecies.org/aphia.php? $\mathrm{p}=$ taxdetails\&id=135263 on 2020-11-02

1380 Collins, R.A., Cruickshank, R.H., 2013. The seven deadly sins of DNA barcoding. Mol

1381 Ecol Res, 13, 969-975. http://doi.org/10.1111/1755-0998.12046

1382 Conix, S., (2018). Integrative taxonomy and the operationalization of evolutionary

1383 independence. Euro Jnl Phil Sci, 8(3), 587-603. https://doi.org/10.1007/s13194-018-0202-z

1384 Cortés, J., 1996. Biodiversidad marina de Costa Rica: Filo Cnidaria. Rev Biol Trop, 44,

1385 323-334. http://revistas.ucr.ac.cr/index.php/rbt/article/view/22058

1386 Costello, M.J., Tsai, P., Wong, P.S., Cheung, A.K.L., Basher, Z., Chaudhary, C., 2017.

1387 Marine biogeographic realms and species endemicity. Nat Commun, 8(1057), 1-9.

1388 http://doi.org/10.1038/s41467-017-01121-2

1389 Coyne, J.A., Orr, H.A., 2004. Speciation, Sinaeur Assoc, USA. 
1390 Cunha, A.F., Genzano, G.N., Marques, A.C., 2015. Reassessment of morphological 1391 diagnostic characters and species boundaries requires taxonomical changes for the genus

1392 Othopyxis L. Agassiz, 1862 (Campanulariidae, Hydrozoa) and some related campanulariids. Plos 1393 one, 10(2), e0117553, 1-35. http://doi.org/10.1371/journal.pone.0117553

1394 D’Ambra, I., Graham, W.M., 2009. Early developmental sequence of an anthozoan

1395 parasite of the jellyfish Aurelia sp. 5 in an isolated marine lake (Mljet, Croatia). Ann Ser Hist

1396 Nat, 19, 59-64. http://www.dlib.si/stream/URN:NBN:SI:DOC-M6KV9WYH/bb9bdf5b-8589-

1397 4cdd-885a-ff21fb2a3350/PDF

1398 D’Ambra, I., Graham, W.M., Carmichael, R.H., Malej, A., Onofri, V., 2013. Predation

1399 patterns and prey quality of medusae in a semi-enclosed marine lake: Implications for food web

1400 energy transfer in coastal marine ecosystems. J Plankton Res, 35, 1305-1312.

1401 http://doi.org/10.1093/plankt/fbt065

1402 Davis, J.I., Nixon, K.C., 1992. Populations, genetic variation, and the delimitation of

1403 phylogenetic species. Syst Biol, 41, 421-435. http://doi.org/10.1093/sysbio/41.4.421

1404 Dawson, M.N., Jacobs, D.K., 2001. Molecular evidence for cryptic species of Aurelia

1405 aurita (Cnidaria, Scyphozoa). Biol Bull, 200, 92-96. http://doi.org/10.2307/1543089

1406 Dawson, M.N., Martin, D.L., 2001. Geographic variation and ecological adaptation in

1407 Aurelia aurita (Scyphozoa, Semaestomeae): some implications from molecular phylogenetics.

1408 Hydrobiologia, 451, 259-273. http://doi.org/10.1023/A:1011869215330

1409 Dawson, M.N., 2003. Macro-morphological variation among cryptic species of the moon

1410 jellyfish, Aurelia (Cnidaria: Scyphozoa). Mar Biol, 143, 369-379. http://doi.org/10.1007/s00227-

1411 003-1070-3

1412 Dawson, M.N., Gupta, A.S., England, M.H., 2005. Coupled biophysical global ocean

1413 model and molecular genetic analyses identify multiple introductions of cryptogenic species.

1414 Pnas, 102, 11968-11973. http://doi.org/10.1073/pnas.0503811102

1415 Dayrat, B., 2005. Towards integrative taxonomy, Biol J Linn Soc, 85, 407-415.

1416 http://doi.org/10.1111/j.1095-8312.2005.00503.x

1417 Delić, T., Trontelj, P., Rendoš, M., Fišer, C., 2017. The importance of naming cryptic

1418 species and the conservation of endemic subterranean amphipods. Sci Rep, 7, 3391.

1419 http://doi.org/10/1038/s41598-017-02938-z

1420 DeSalle, R., Goldstein, P., 2019. Review and Interpretation of Trends in DNA Barcoding.

1421 Front Ecol Evol, 7. http://doi.org/10.3389/fevo.2019.00302

1422 Dong, Z., Liu, Z., Liu, D., 2015. Genetic characterization of the scyphozoan jellyfish

1423 Aurelia spp. in Chinese coastal waters using mitochondrial markers. Biochem Syst Ecol, 60, 15-

1424 23. http://doi.org/10.1016/j.bse.2015.02.018

1425 Dong, Z., Sun, T., Liu, Q., Sun, Y., 2017. High density aggregations of the Aurelia sp. 1

1426 ephyrae in a Chinese coastal aquaculture pond. Aquat Ecosyst Health, 20, 465-471.

1427 http://www.tandfonline.com/doi/full/10.1080/14634988.2017.1362627

1428 Dong, Z., 2018. Blooms of the Moon Jellyfish Aurelia: Causes, Consequences and

1429 Controls, in Sheppard, C. (Ed.), World Seas: An Environmental Evaluation (Second Edition), 
1430 Volume III: Ecological Issues and Environmental Impacts. Elsevier Ltd., pp. 163-171.

1431 http://doi.org/10.1016/B978-0-12-805052-1.00008-5

1432 Eitel, M., Francis, W.R., Varoqueaux, F., Daraspe, J., Osigus, H.J., Krebs, S., Vargas, S.,

1433 Blum, H., Williams, G.A., Schierwater, B., Wörheide, G., 2018. Comparative genomics and the

1434 nature of placozoan species. Plos Biol, 16, 1-36. http://doi.org/10.1371/journal.pbio.2005359

1435 Fetzner, J.W., 1999. Extracting High-Quality DNA from Shed Reptile Skins: A

1436 Simplified Method. Biotechniques, 26, 1052-1054. http://doi.org/10.2144/99266bm09

1437 Forskål, P., 1775. Descriptiones animalium, avium, amphibiorum, piscium, insectorum,

1438 vermium / quae in itinere orientali observavit Petrus Forskål. Post mortem auctoris edidit Carsten

1439 Niebuhr. Adjuncta est materia medica kahirina atque tabula maris Rubris geographica. Hauniae

1440 [Copenhagen], ex officina Mölleri. https://www.biodiversitylibrary.org/page/2088059

1441 Francis, L., 2004. Microscaling: why larger anemones have longer cnidae. Biol Bull, 207,

1442 116-129. http://doi.org/10.2307/1543586

1443 Frolova, A., Miglietta, M.P., 2020. Insights on Bloom Forming Jellyfish (Class:

1444 Scyphozoa) in the Gulf of Mexico: Environmental Tolerance Ranges and Limits Suggest

1445 Differences in Habitat Preference and Resistance to Climate Change Among Congeners. Front

1446 Mar Sci, 7. http://doi.org/10.3389/fmars.2020.00093

1447 Frost, D.R., Kluge, A.G., 1994. A consideration of epistemology in systematic biology,

1448 with special reference to species. Cladistics, 10, 259-294. http://doi.org/10.1111/j.1096-

1449 0031.1994.tb00178.x

1450 Frost, D.R., Crafts, H.M., Fitzgerald, L.A., Titus, T.A., 1998. Geographic variation,

1451 species recognition, and molecular evolution of cytochrome oxidase I in the Tropidurus

1452 spinulosus comples (Iguania: Tropiduridae). Copeia, 1998, 839-851.

1453 http://doi.org/10.2307/1447331

1454 Frost, D.R., 2000. Species, descriptive efficiency and progress in systematics, in: Bruce,

1455 R.C., Jaeger, R.G., Houck, L.D. (Eds.), The biology of plethodontid salamanders. Plenum

1456 Publishers, New York, pp. 7-29. http://doi.org/10.1007/978-1-4615-4255-1_2

1457 Gambill, M., Jarms, G., 2014. Can Aurelia (Cnidaria, Scyphozoa) species be

1458 differentiated by comparing their scyphistomae and ephyrae? Eur J Tax, 107, 1-23.

1459 http://doi.org/10.5852/ejt.2014.107

1460 Gershwin, L., 2001. Systematics and biogeography of the jellyfish Aurelia labiata

1461 (Cnidaria: Scyphozoa). Biol Bull, 201, 104-119. http://doi.org/10.2307/1543531

1462 Goette, A., 1887. Entwickelungsgeschichte der Aurelia aurita und Cotylorhiza

1463 tuberculata. Abhandlungen zur Entwickelungsgeschichte der Tiere, 4, 1-79.

1464 Goldstein, P.Z., DeSalle, R., 2011. Integrating DNA barcode data and taxonomic

1465 practice: Determination, discovery, and description. BioEssays, 33, 135-147.

1466 http://doi.org/10.1002/bies.201000036

1467 Goloboff, P.A., 1999. Analyzing large data sets in reasonable times: solutions for

1468 composite optima. Cladistics, 15, 415-428. http://doi.org/10.1111/j.1096-0031.1999.tb00278.x

PeerJ reviewing PDF | (2021:04:60391:1:0:NEW 8 Jul 2021) 
1469

1470

1471

1472

1473

1474

1475

1476

1477

1478

1479

1480

1481

1482

1483

1484

1485

1486

1487

1488

1489

1490

1491

1492

1493

1494

1495

1496

1497

1498

1499

1500

1501

1502

1503

1504

1505

1506

1507

Goloboff, P.A., Catalano, S.A., 2016. TNT version 1.5, including a full implementation of phylogenetic morphometrics. Cladistics, 32, 221-238. http://doi.org/10.111/cla.12160

Gómez-Daglio, L., Dawson, M.N., 2017. Species richness of jellyfishes (Scyphozoa: Discomedusae) in the Tropical Eastern Pacific: missed taxa, molecules, and morphology match in a biodiversity hotspot. Invertebr Syst, 31, 635-663.

http://doi.org/http://dx.doi.org/10.1071/IS16055

Gómez-Daglio, L., Dawson, M.N., 2019. Integrative taxonomy: Ghosts of past, presente and future. J Mar Biol Assoc UK, 99, 1237-1246. http://doi.org/10.1017/S0025315419000201

Goodman, M., Olson, C.B., Beeber, J.E., Czelusniak, J., 1982. New perspectives in the molecular biological analysis of mammalian phylogeny. Acta Zool Fenn, 169, 19-35.

Goy, J., 1979. Campagne de la Calypso au large des côtes atlantiques de l'Amérique du Sud (1961-1962) - 35 Méduses. Resultats scientifiques des campagnes de la Calypso, 11, 263296.

Grant, T., 2002. Testing methods: The evaluation of discovery operations in evolutionary biology. Cladistics, 18, 94-111. http://doi.org/10.1006/clad.2002.0186

Grant, T., Kluge, A.G., 2004. Transformation series as an ideographic character concept. Cladistics, 20, 23-31. http://doi.org/10.1111/j.1096-0031.2004.00003.x

Grant, T., Frost, D.R., Caldwell, J.P., Gagliardo, R., Haddad, C.F.B., Kok, P. J.R., Means, D.B., Noonan, B.P., Schargel, W.E., Wheeler, W.C., 2006. Phylogenetic Systematics of Dart-Poison Frogs and Their Relatives (Amphibia: Athesphatanura: Dendrobatidae). B Am Mus Nat Hist, 299, 1-262. http://doi.org/10.1206/0003-0090(2006)299[1:PSODFA]2.0.CO;2

Grant, T., Kluge, A.G., 2008. Credit where credit is due: The Goodman-Bremer support metric. Mol Phylogenet Evol, 49, 405-406. http://doi.org/10.1016/j.ympev.2008.04.023

Guindon, S., Dufayard, J-F., Lefort, V., Anisimova, M., Hordijk, W., Gascuel, O., 2010. New algorithms and methods to estimate maximum-likelihood phylogenies:assessing the performance of PhyML 3.0. Syst Biol, 59, 307-321. http://doi.org/10.1093/sysbio/syq010

Haeckel, E., 1880. Das System der Medusen. I, 2: System der Acraspeden, Jena, Fischer. http://doi.org/10.5962/bhl.title.46856

Hamilton, G., 2016. The secret lives of jellyfish. Nature, 531, 432-434.

http://doi.org/10.1038/531432a

Häussermann, V., Dawson, M.N., Försterra, G., 2009. First record of the moon jellyfish, Aurelia for Chile. Spixiana, 32, 3-7.

Hays, G., Doyle, T., Houghton, J., 2018. A paradigm shift in the trophic importance of jellyfish? Trends Ecol Evol, 33, 874-884. http://doi.org/10.1016/j.tree.2018.09.001

He, J., Zheng, L., Zhang, W., Lin, Y., 2015. Life cycle reversal in Aurelia sp.1 (Cnidaria, Scyphozoa). Plos one, 10, 1-14. http://doi.org/10.1371/journal.pone.0145314

Hebert, P.D.N., Cywinska, A., Ball, S.L., DeWaard, J.R., 2003. Biological identifications through DNA barcodes. P Roy Soc B-Biol Sci, 270, 313-321.

http://doi.org/10.1098/rspb.2002.2218 
1508

1509

1510

1511

1512

1513

1514

1515

1516

1517

1518

1519

1520

1521

1522

1523

1524

1525

1526

1527

1528

1529

1530

1531

1532

1533

1534

1535

1536

1537

1538

1539

1540

1541

1542

1543

1544

1545

1546

1547

Hebert, P.D.N., Penton, E.H., Burns, J.M., Janzen, D.H., Hallwachs, W., 2004. Ten species in one: DNA barcoding reveals cryptic species in the neotropical skipper butterfly Astraptes fulgerator. Pnas, 101, 14812-14817. http://doi.org/10.1073/pnas.0406166101

Hennig, W., 1966. Phylogenetic systematics, University of Illinois Press, USA.

Holst, S., Laakmann, S., 2014. Morphological and molecular discrimination of two closely related jellyfish species, Cyanea capillata and C. lamarckii (Cnidaria, Scyphozoa), from the northeast Atlantic. J Plankton Res, 36, 48-63. http://doi.org/10.1093/plankt/fbt093

Hütter, T., Ganser, M.H., Kocher, M., Halkic, M., Agatha, S., Augsten, N., 2020. DeSignate: detecting signature characters in gene sequence alignments for taxon diagnoses. BMC Bioinformatics, 21, 151. http://doi.org/10.1186/s12859-020-3498-6

ICZN (Internation Comission on Zoological Nomenclature), 1999. International code of zoological nomenclature, Fourth Edition, London.

Jarms, G., Morandini, A.C., 2019. World Atlas of Jellyfish: Scyphozoa except Stauromedusae. Hamburg: Dölling und Galitz Verlag. 816p.

Jörger, K., Schrödl, M., 2013. How to describe a cryptic species? Practical challenges of molecular taxonomy. Front Zool, 10, 1-27. http://doi.org/10.1186/1742-9994-10-59

Kalyaanamoorthy, S., Minh, B.Q., Wong, T.K.F., von Haeseler, A., Jermiin, L.S., 2017. ModelFinder: Fast Model Selection for Accurate Phylogenetic Estimates. Nature Methods, 14, 587-589. http://doi.org/10.1038/nmeth.4285

Katoh, K., Standley, D.M., 2013. MAFFT Multiple Sequence Alignment Software version 7: improvements in performance and usability. Mol Biol Evol, 30, 772-780. http://doi.org/10.1093/molbev/mst010

Kearse, M., Moir, R., Wilson, A., Stones-Havas, S., Cheung, M., Sturrock, S., Buxton, S., Cooper, A., Markowitz, S., Duran, C., Thierer, T., Ashton, B., Meintjes, P., Drummond, A., 2012. Geneious Basic: an integrated and extendable desktop software platform for the organization and analysis of sequence data. Bioinformatics 28, 1647-1649.

http://doi.org/10.1093/bioinformatics/bts199

Ki, J.S., Hwang, D.S., Shin, K., Yoon, W.D., Lim, D., Kang, Y.S., Lee, Y., Lee, J.S., 2008. Recent moon jelly (Aurelia sp.1) blooms in Korean coastal waters suggest global expansion: Examples inferred from mitochondrial COI and nuclear ITS-5.8S rDNA sequences. ICES J Mar Sci, 65, 443-452. http://doi.org/10.1093/icesjms/fsn018

Kluge, A.G., 1990. Species as historical individuals. Biol Phil, 5, 417-431. http://doi.org/10.1007/BF02207380

Kogovšek, T., Molinero, J.C., Lučić, D., Onofri, I., Gangai, B., Miloslavić, M., Bonnet, D., Malej, A., 2012. Interannual size changes of adult Aurelia sp. 5 medusae stage in the Marine Protected Area of Mljet Island South Adriatic. Acta Adriat, 53, 231-240.

http://jadran.izor.hr/acta/pdf/53_2_pdf/53_2_5.pdf

Korsun, S., Fahrni, J.F., Pawlowski, J., 2012. Invading Aurelia aurita has established scyphistoma populations in the Caspian Sea. Mar Biol, 159, 1061-1069.

http://doi.org/10.1007/s00227-012-1886-9

PeerJ reviewing PDF | (2021:04:60391:1:0:NEW 8 Jul 2021) 
1548

1549

1550

1551

1552

1553

1554

1555

1556

1557

1558

1559

1560

1561

1562

1563

1564

1565

1566

1567

1568

1569

1570

1571

1572

1573

1574

1575

1576

1577

1578

1579

1580

1581

1582

1583

1584

1585

1586

Kramp, P.L., 1961. Synopsis of the medusae of the world. J Mar Biol Assoc UK, 40, 7469. http://doi.org/10.1017/S0025315400007347

Kramp, P.L., 1965. Some medusae (mainly Scyphomedusae) from Australian coastal waters. T Roy Soc South Aust, 89, 257-278.

Kramp, P.L., 1968. The scyphomedusae collected by the Galathea Expedition 1950-52. Vidensk Meddr Dansk Naturh Foren, 31, 67-98.

Kühn, A.L., Haase, M., 2019. QUIDDICH: Quick Identification of Diagnostic Characters. J Zool Syst Evol Res, 58, 22-26. http://doi.org/10.1111/jzs.12347

Lamarck, J.-B.M. de, 1816. Histoire naturelle des animaux sans vertèbres. Paris, Verdière, Tome second, 568 pp. http://www.biodiversitylibrary.org/item/47698

Lampert, K.P., Bürger, P., Striewski, S., Tollrian, R., 2011. Lack of association between color morphs of the jellyfish Cassiopea andromeda and zooxanthella clade. Mar Ecol, 33, 364369. http://doi.org/10.1111/j.1439-0485.2011.00488.x

Larson, R.J., 1990. Scyphomedusae and Cubomedusae from the Eastern Pacific. Bull Mar Sci, 47, 546-556. http://www.ingentaconnect.com/content/umrsmas/bullmar/1990/00000047/00000002/art00010 Lawley, J.W., Ames, C.L., Bentlage, B., Yanagihara, A., Goodwill, R., Kayal, E., Hurwitz, K., Collins, A.G., 2016. Box jellyfish Alatina alata has a circumtropical distribution. Biol Bull, 231, 152-169. http://doi.org/10.1086/690095

Lawley, J.W., Gamero-Mora, E., Maronna, M.M., Chiaverano, L.M., Stampar, S.N., Hopcroft, R.R., Collins, A.G., Morandini, A.C., 2021. Genetic data for Aurelia systematics. Figshare. Dataset. https://doi.org/10.6084/m9.figshare.14502474.v1

Lesson, R.P., 1830. Zoophytes, in: Lesson, M. (Ed.), Voyage autour du monde, execute par ordre du Roi, sur la Corvette de la Majesté, La Coquile, pendant les années 1822, 1823, 1824 et 1825. Arthus Bertrand, Paris, Vol. II, $2^{\mathrm{e}}$ partie (Zoologie), $2^{\mathrm{e}}$ division. https://www.biodiversitylibrary.org/item/119038\#page/335/mode/1up

Linnaeus, C., 1758. Systema Naturae per regna tria naturae, secundum classes, ordines, genera, species, cum characteribus, differentiis, sinonimis, locis. Editio decima, reformata. Tomus I. Laurentii Salvii, Holmiae, 828 pp. https://biodiversitylibrary.org/page/726886 Lleonart, J., Salat, J., Torres, G.J., 2000. Removing allometric effects of body size in morphological analysis. J Theor Biol, 278, 85-93. http://doi.org/10.1006/jtbi.2000.2043 Machado, D.J., 2015. YBYRÁ facilitates comparison of large phylogenetic trees. BMC Bioinformatics, 16, 1-4. http://doi.org/10.1186/s12859-015-0642-9

Maggioni, D., Montano, S., Arrigoni, R., Galli, P., Puce, S., Pica, D., Berumen, M.L., 2017. Genetic diversity of the Acropora-associated hydrozoans: new insight from the Red Sea. Mar Biodivers, 47, 1045-1055. http://doi.org/10.1007/s12526-017-0632-4

Malej, A., Turk, V., Lučić, D., Benović, A., 2007. Direct and indirect trophic interactions of Aurelia sp. (Scyphozoa) in a stratified marine environment (Mljet Lakes, Adriatic Sea). Mar Biol, 151, 827-841. http://doi.org/10.1007/s00227-006-0503-1 
1587 Malej, A., Turk, V., Kogovšek, T., Makovec, T., Onofri, V., Chiaverano, L., Tinta, T., 1588 Flander-Putrle, V., Lučić, D., 2009. Aurelia sp. 5 (Scyphozoa) Population in the Mljet Lake (the

1589 Southern Adriatic): Trophic Interactions and Link to Microbial Food Web. Ann Ser Hist Nat, 19, 1590 49-58. http://www.dlib.si/stream/URN:NBN:SI:DOC-CSPIRJDV/6bb7800b-a448-40e9-bc46-

$1591 \quad 34 \mathrm{fa} 9 \mathrm{~b} 212 \mathrm{e} 75 / \mathrm{PDF}$

1592 Manzari, C., Fosso, B., Marzano, M., Annese, A., Caprioli, R., D’Erchia, A.M., Gissi, C., 1593 Intranuovo, M., Picardi, E., Santamaria, M., Scorrano, S., Sgaramella, G., Stabili, L., Piraino, S., 1594 Pesole, G., 2015. The influence of invasive jellyfish blooms on the aquatic microbiome in a 1595 coastal lagoon (Varano, SE Italy) detected by an Illumina-based deep sequencing strategy. Biol 1596 Invasions, 17, 923-940. http://doi.org/10.1007/s10530-014-0810-2 1597 Marques, R., Albouy-Boyer, S., Delpy, F., Carré, C., Le Floc'h, É., Roques, C., 1598 Molinero, J., Bonnet, D., 2014. Pelagic population dynamics of Aurelia sp. in French 1599 Mediterranean lagoons. J Plankton Res, 37, 1019-1035. http://doi.org/10.1093/plankt/fbv059 1600 Mayer, A.G.,1910. The medusae of the world. Volume III. The Scyphomedusae.

1601 Carnegie Inst Washington Publ 109, 499-735. http://doi.org/10.5962/bhl.title.5996

1602 Meyer, C. P., Paulay, G., 2005. DNA barcoding: error rates based on comprehensive 1603 sampling. Plos Biol, 3, 12, e422. http://doi.org/10.1371/journal.pbio.0030422

1604 Mianzan, H.W., Cornelius, P.F.S., 1999. Cubomedusae and Scyphomedusae, in:

1605 Boltovskoy, D. (Ed.), South Atlantic Zooplankton. Backhuys Publishers, Leiden, pp. 513-559.

1606 http://species-

1607 identification.org/species.php?species group=zsao\&menuentry=inleiding\&record=Cubomedusa 1608 e\%20and\%20Scyphomedusae

1609 Miloslavić, M., Garić, R., Lučić, P., Maguire, I., Lučić, D., 2016. Ecology and population 1610 structure of the hyperbenthic copepod Mesaiokeras hurei Kršinić, 2003 (Calanoida:

1611 Mesaiokeratidae) from an isolated marine lake (Mljet island, Southern Adriatic Sea, Croatia). J

1612 of Crustacean Biol, 36, 295-302. http://doi.org/10.1163/1937240X-00002421

1613 Miyake, H., Lindsay, D.J., Hunt, J.C., Hamatsu, T., 2002. Scyphomedusa Aurelia limbata

1614 (Brandt, 1838) found in deep waters off Kushiro, Hokkaido, Northern Japan. Plankton Biol Ecol, 1615 49, 44-46. http://www.plankton.jp/PBE/issue/vol49 1/vol49 1 044.pdf

1616 Mizrahi, G., 2014. Phylogenetic Analysis of Gelatinous Marine Fauna in the Eastern

1617 Mediterranean Basin - An Ecosystem under Anthropogenic Stress. PhD thesis, University of

1618 Haifa, Israel.

1619 http://digitool.haifa.ac.il//exlibris/dt1/d3 1/apache media/L2V4bGlicmlzL2R0bC9kM18xL2Fw 1620 YWNoZV9tZWRpYS84NTk4NDU=.pdf

1621 Nagy, L.G., Kocsubé, S., Csanádi, Z., Kovács, G.M., Petkovics, T., Vágvölgyi, C., Pap, 1622 T., 2012. Re-Mind the Gap! Insertion - Deletion data reveal neglected phylogenetic potential of 1623 the nuclear ribosomal internal transcribed spacer (ITS) of Fungi. Plos one, 7, 1-9.

1624 http://doi.org/10.1371/journal.pone.0049794 
1625

1626

1627

1628

1629

1630

1631

1632

1633

1634

1635

1636

1637

1638

1639

1640

1641

1642

1643

1644

1645

1646

1647

1648

1649

1650

1651

1652

1653

1654

1655

1656

1657

1658

1659

1660

1661

1662

1663

1664

Nguyen, L.T., Schmidt, H.A., von Haeseler, A., Minh, B.Q., 2015. IQ-TREE: a fast and effective stochastic algorithm for estimating maximum-likelihood phylogenies. Mol Biol Evol, 32, 268-274. http://doi.org/10.1093/molbev/msu300

Nixon, K.C., 1999. The parsimony ratchet, a new method for rapid parsimony analysis. Cladistics, 15, 407-414. http://doi.org/10.1006/clad.1999.0121

Ortman, B.D., Bucklin, A., Pages, F., Youngbluth, M., 2010. DNA barcoding the Medusozoa using mtCOI. Deep-Sea Res Pt II, 57, 2148-2156.

http://doi.org/10.1016/j.dsr2.2010.09.017

Pantin, C.F.A., Dias, M.V., 1952. Rhythm and after-discharge in medusa. Anais Acad Bras Cienc, 24, 351-364.

Paz, G., Rinkevich, B., 2020. Gap-analysis of DNA barcoding in ERMS reference libraries for ascidians and cnidarians. Preprint (version 2) available at Research Square http://doi.org/10.21203/rs.3.rs-50653/v2

Pfenninger, M., Schwenk, K., 2007. Cryptic animal species are homogeneously distributed among taxa and biogeographical regions. BMC Evol Biol, 7, 1-6.

http://doi.org/10.1186/1471-2148-7-121

Pleijel, F., Jondelius, U., Norlinder, E., Nygren, A., Oxelman, B., Schander, C., Sundberg, P., Thollesson, M., 2008. Phylogenies without roots? A plea for the use of vouchers in molecular phylogenetic studies. Mol Phylogenet Evol, 48, 369-371.

http://doi.org/10.1016/j.ympev.2008.03.024

Prendini, L., 2005. Comment on 'identifying spiders through DNA barcoding'. Can J Zool, 83, 498-504. http://doi.org/10.1139/z05-025

R Core Team, 2020. R: A Language and Environment for Statistical Computing. R Foundation for Statistical Computing, Vienna. http://www.r-project.org/.

Ramšak, A., Stopar, K., Malej, A., 2012. Comparative phylogeography of meroplanktonic species, Aurelia spp. and Rhizostoma pulmo (Cnidaria: Scyphozoa) in European Seas. Hydrobiologia, 690, 69-80. http://doi.org/10.1007/s10750-012-1053-9

Ransome, E., Geller, J., Timmers, M., Leray, M., Sembiring, A., Collins, A.G., Meyer, C., 2017. The Importance of Standardization for Global Comparisons: a case study using Autonomous Reef Monitoring Structures (ARMS) and metabarcoding to measure cryptic diversity on Mo'orea coral reefs, French Polynesia. Plos one, 12, e0175066. http://doi.org/10.1371/journal.pone.0175066

Ruijuan, L., Jie, X., Xuelei, Z., Aungtonya, C., 2016. Genetic analysis of common venomous Cubozoa and Scyphozoa in Thailand waters. Haiyang Xuebao, 38, 51-61. http://doi.org/10.3969/j.issn.0253-4193.2016.06.006

Russell, F.S., 1970. The medusae of the British Isles II. Pelagic Scyphozoa with a supplement to the first volume on hydromedusae. Cambridge University Press, London.

Sarkar, I.N., Planet, P.J., DeSalle, R., 2008. CAOS software for use in character-based DNA barcoding. Mol Ecol Resour, 8, 1256-1259. http://doi.org/10.1111/j.17550998.2008.02235.X 
1665 Schindelin, J., Arganda-Carreras, I., Frise, E., Kaynig, V., Longair, M., Pietzsch, T.,

1666

1667

1668

1669

1670

1671

1672

1673

1674

1675

1676

1677

1678

1679

1680

1681

1682

1683

1684

1685

1686

1687

1688

1689

1690

1691

1692

1693

1694

1695

1696

1697

1698

1699

1700

1701

1702

1703

Preibisch, S., Rueden, C., Saalfeld, S., Schmid, B., Tinevez, J., White D.J., Hartenstein, V., Eliceiri, K., Tomancak, P., Cardona, A. 2012. Fiji: an open-source platform for biological-image analysis. Nature methods, 9, 676-682. http://doi.org/10.1038/nmeth.2019

Schroth, W., Jarms, G., Streit, B., Schierwater, B., 2002. Speciation and phylogeography in the cosmopolitan marine moon jelly, Aurelia sp. BMC Evol Biol., 2, 1-10.

http://doi.org/10.1186/1471-2148-2-1

Scorrano, S., Aglieri, G., Boero, F., Dawson, M.N., Piraino, S., 2016. Unmasking Aurelia species in the Mediterranean Sea: An integrative morphometric and molecular approach. Zool J Linn Soc-Lond, 180, 243-267. http://doi.org/10.1111/zoj.12494

Sherman, K., 1991. The Large Marine Ecosystem Concept: Research and Management Strategy for Living Marine Resources. Ecol Appl, 1, 349-360. http://doi.org/10.2307/1941896

Skinner, A., 2004. Hierarchy and monophyly. Cladistics, 20, 498-500.

http://doi.org/10.111/j.1096-0031.2004.00036.X

Stampar, S.N., Maronna, M.M., Vermeij, M.J.A., Silveira, F.L., Morandini, A.C., 2012. Evolutionary diversification of banded tube-dwelling anemones (Cnidaria; Ceriantharia; Isarachnanthus) in the Atlantic Ocean. Plos one, 7, 1-11.

http://doi.org/10.1371/journal.pone.0041091

Struck, T.H., Feder, J.L., Bendiksby, M., Birkeland, S., Cerca, J., Gusarov, V.I., Kistenich, S., Larsson, K., Liow, L.H., Nowak, M.D., Stedje, B., Bachmann, L., Dimitrov, D., 2017. Finding Evolutionary Processes Hidden in Cryptic Species. Trends Ecol Evol, 33, 153163. http://doi.org/10.1016/j.tree.2017.11.007

Swift, H.F., Gómez-Daglio, L., Dawson, M.N., 2016. Three routes to crypsis: Stasis, convergence, and parallelism in the Mastigias species complex (Scyphozoa, Rhizostomeae). Mol Phylogenet Evol, 99, 103-115. http://doi.org/10.1016/j.ympev.2016.02.013

Tinta, T., Malej, A., Kos, M., Turk, V., 2010. Degradation of the Adriatic medusa Aurelia sp. by ambient bacteria. Hydrobiologia, 645, 179-191. http://doi.org/10.1007/s10750010-0223-x

Trontelj, P., Fišer, C., 2009. Cryptic species diversity should not be trivialised. Syst Biodivers, 7, 1-3. http://doi.org/10.1017/S1477200008002909

Turk, V., Lučić, D., Flander-Putrle, V., Malej, A., 2008. Feeding of Aurelia sp. (Scyphozoa) and links to the microbial food web. Mar Ecol, 29, 495-505. http://doi.org/10.1111/j.1439-0485.2008.00250.x

Vaidya, G., Lohman, D.J., Meier, R., 2011. SequenceMatrix: concatenation software for the fast assembly of multi-gene datasets with character set and codon information. Cladistics, 27, 171-180. http://doi.org/10.1111/j.1096-0031.2010.00329.x

Valdecasas, A.G., Williams, D., Wheeler, Q.D., 2008. 'Integrative taxonomy' then and now: a response to Dayrat (2005). Biol J Linn Soc, 93, 211-216. http://doi.org/10.1111/j.1095$\underline{8312.2007 .00919 . x}$

PeerJ reviewing PDF | (2021:04:60391:1:0:NEW 8 Jul 2021) 
1704 Vanhöffen, E., 1888. Untersuchungen über semäostome und rhizostome Medusen.

1705

1706

1707

1708

1709

1710

1711

1712

1713

1714

1715

1716

1717

1718

1719

1720

1721

1722

1723

1724

1725

1726

1727

1728

1729

1730

1731

1732

1733

1734

1735

Bibliotheca Zoologica, 1, 5-52. https://www.biodiversitylibrary.org/item/85310

Vannucci, M., 1957. Distribuição de Scyphozoa nas costas do Brasil. An Acad Bras Cienc, 29, 593-598.

Verrill, A.E., 1865. Classification of polyps. Proc Essex Inst, 4, 145-152.

https://www.biodiversitylibrary.org/page/34752272

Virgilio, M., Jordaens, K., Breman, F.C., Backeljau, T., Meyer, M., 2012. Identifying

insects with incomplete DNA barcode libraries, African fruit flies (Diptera: Tephritidae) as a test case. Plos one, 7, 1-8. http://doi.org/10.1371/journal.pone.0031581

von Lendenfeld, R., 1884. The scyphomedusae of the southern hemisphere. Part III. Proceedings of the Linnean Society of New South Wales, 9, 259-306.

https://www.biodiversitylibrary.org/page/6602498

Wang, Y.T., Sun, S., 2014. Population dynamics of Aurelia sp. 1 ephyrae and medusae in Jiaozhou Bay, China. Hydrobiologia, 754, 147-155. http://doi.org/10.1007/s10750-014-2021-3

Webb, K.E., Barnes, D.K.A., Clark, M.S., Bowden, D.A., 2006. DNA barcoding: A molecular tool to identify Antarctic marine larvae. Deep-Sea Res Pt II, 53, 1053-1060. http://doi.org/10.1016/j.dsr2.2006.02.013

Wheeler, W.C., 1996. Optimization Alignment: the end of multiple sequence alignment in phylogenetics? Cladistics, 12, 1-9. http://doi.org/10.1111/j.1096-0031.1996.tb00189.x

Wheeler, W.C., 2001. Homology and the optimization of DNA sequence data. Cladistics, 17, S3-S11. http://doi.org/10.1006/clad.2000.0154

Wheeler, W.C., 2003a. Iterative pass optimization. Cladistics, 19, 254-260.

http://doi.org/10.1111/j.1096-0031.2003.tb00368.x

Wheeler, W.C., 2003b. Implied alignment: a synapomorphy based multiple-sequence alignment method and its use in cladogram search. Cladistics, 19, 261-268.

http://doi.org/10.1111/j.1096-0031.2003.tb00369.x

Wheeler, W.C., Lucaroni, N., Hong, L., Crowley, L.M., Varón, A., 2014. POY version 5: phylogenetic analysis using dynamic homologies under multiple optimality criteria. Cladistics, 31, 189-196. http://doi.org/10.1111/cla.12083

Wiemers, M., Fiedler, K., 2007. Does the DNA barcoding gap exist? - A case study in blue butterflies (Lepidoptera: Lycaenidae). Front Zool, 4, 1-16. http://doi.org/10.1186/1742$\underline{9994-4-8}$

PeerJ reviewing PDF | (2021:04:60391:1:0:NEW 8 Jul 2021) 


\section{Table $\mathbf{1}$ (on next page)}

Institutions from which specimens were observed for morphological analyses and included in this study.

$\mathrm{N}=$ number of specimens. Preserved samples were mostly in $4-5 \%$ formalin, but sometimes in $70 \%$ ethanol. Acronyms of other institutions cited, mostly in the species descriptions are as follows: CAS/CASIZ = California Academy of Sciences, Invertebrate Zoology, USA; MCZ = Museum of Comparative Zoology, Harvard, USA; NHM = The Natural History Museum, United Kingdom; UNIPD = Museum of Adriatic Zoology Giuseppe Olivi, Italy; UNIS_SCY = Laboratory of Zoology and Marine Biology in the University of Salento, Italy. 
1 Table 1. Institutions from which specimens were observed for morphological analyses and 2 included in this study. $\mathrm{N}=$ number of specimens. Preserved samples were mostly in 4-5\% formalin, 3 but sometimes in $70 \%$ ethanol. Acronyms of other institutions cited, mostly in the species 4 descriptions are as follows: CAS/CASIZ = California Academy of Sciences, Invertebrate Zoology, $5 \mathrm{USA}$; MCZ = Museum of Comparative Zoology, Harvard, USA; NHM = The Natural History 6 Museum, United Kingdom; UNIPD = Museum of Adriatic Zoology Giuseppe Olivi, Italy; 7 UNIS_SCY = Laboratory of Zoology and Marine Biology in the University of Salento, Italy.

\begin{tabular}{|c|c|c|c|c|}
\hline Institution & $\begin{array}{l}\text { City, } \\
\text { Province }\end{array}$ & Country & $\begin{array}{l}\text { Live/ } \\
\text { Preserved }\end{array}$ & $\mathbf{N}$ \\
\hline $\begin{array}{l}\text { Smithsonian Institution's National } \\
\text { Museum of Natural History (USNM) }\end{array}$ & $\begin{array}{l}\text { Washington, } \\
\text { DC }\end{array}$ & USA & Preserved & 81 \\
\hline $\begin{array}{l}\text { Zoological Museum of the University of } \\
\text { Copenhagen (ZMUC) }\end{array}$ & Copenhagen & Denmark & Preserved & 25 \\
\hline $\begin{array}{llll}\text { Yale Peabody } & \text { Museum of Natural } \\
\text { History (YPM) } & & & \end{array}$ & $\begin{array}{l}\text { New Haven, } \\
\text { CT }\end{array}$ & USA & Preserved & 24 \\
\hline $\begin{array}{l}\text { Laboratory for Cnidarian Studies and } \\
\text { Cultivation of the University of São } \\
\text { Paulo (LAB) }\end{array}$ & São Paulo, SP & Brazil & Preserved & 20 \\
\hline Discovery Place (DP) & Charlotte, $\mathrm{NC}$ & USA & Live & 8 \\
\hline $\begin{array}{l}\text { American Museum of Natural History } \\
(\mathrm{AMNH})\end{array}$ & $\begin{array}{ll}\text { New } & \text { York, } \\
\text { NY } & \end{array}$ & USA & Preserved & 5 \\
\hline $\begin{array}{l}\text { Federal University of } \text { Bahia } \\
\text { (UFBA/MZUFBA) }\end{array}$ & Salvador, BA & Brazil & Preserved & 3 \\
\hline $\begin{array}{l}\text { Museum of Zoology of the University of } \\
\text { São Paulo (MZUSP) }\end{array}$ & São Paulo, SP & Brazil & Preserved & 3 \\
\hline National Aquarium (NA) & $\begin{array}{l}\text { Baltimore, } \\
\text { MD }\end{array}$ & USA & Live & 2 \\
\hline Federal University of Ceará (UFC) & Fortaleza, CE & Brazil & Preserved & 1 \\
\hline $\begin{array}{l}\text { Florida Museum of Natural History } \\
\text { (FLMNH/UF) }\end{array}$ & $\begin{array}{l}\text { Gainesville, } \\
\text { FL }\end{array}$ & USA & Preserved & 1 \\
\hline
\end{tabular}




\section{Figure 1}

Subumbrellar (top) and cross-sectional (bottom) views of an Aurelia medusa, illustrating most of the morphological features measured in this study.

Characters from Dawson (2003) span from 1-30 (with modifications indicated by an "a", except for 1a), while novel or from previous studies appear from 31-46. For more details and all features measured see Table S3. (Modified from Dawson, 2003). 


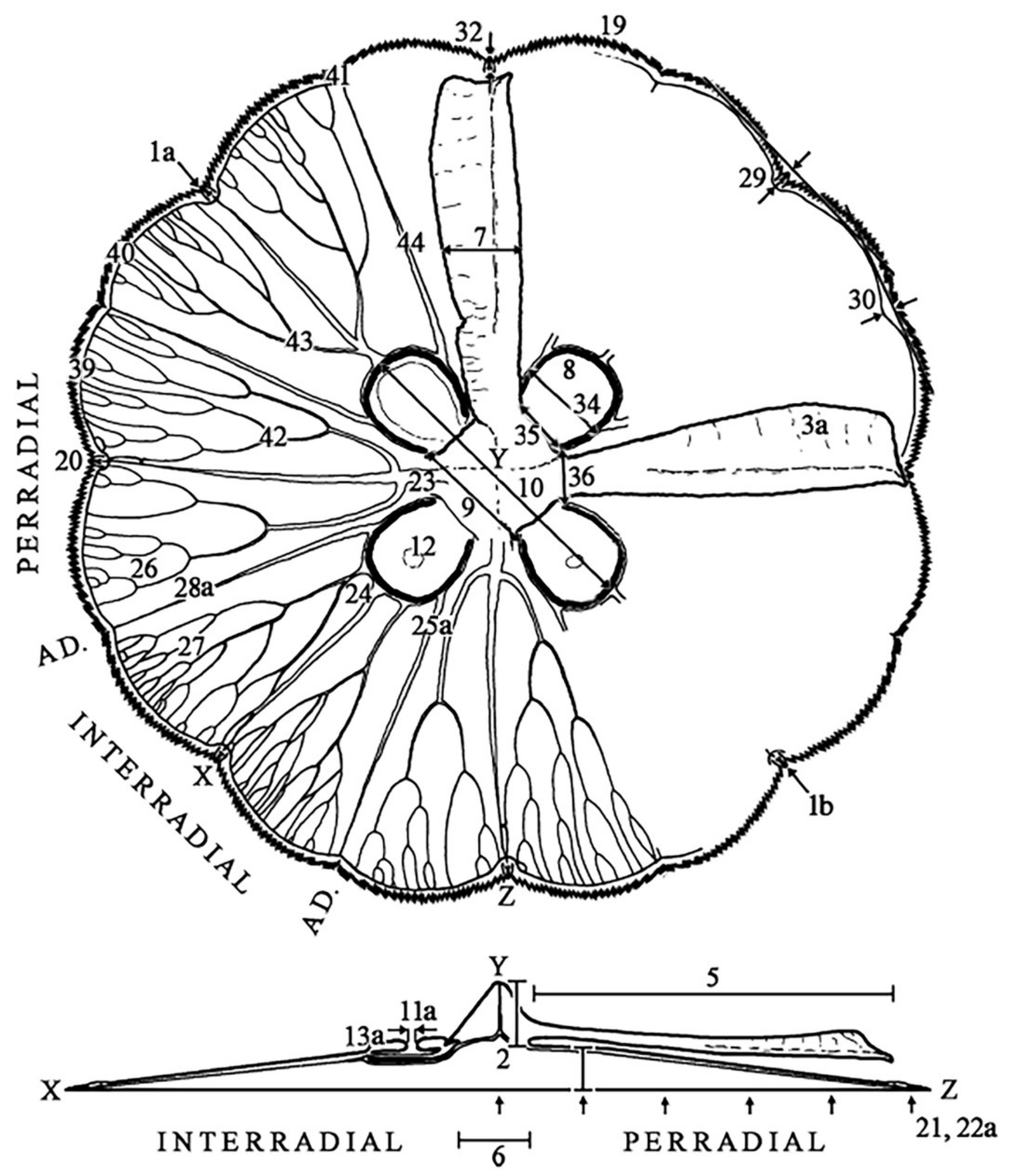


Figure 2

Aurelia medusae in lot YPM 29380, from Massachusetts, USA (highlighted in blue in Figs. 3-4, S1-S2).

$\mathrm{f} 11 \mathrm{a}=$ Lateral sub-genital pore diameter; $\mathrm{f} 34=$ Lateral gastric diameter (furthest points); $\mathrm{f31}$ = Size of gastric pouches; $\mathrm{f3a}=$ Number of oral arm folds (curving points per arm). For more details, see Fig. 1 and Tables S1-S3. Scale $=5 \mathrm{~cm}$. 


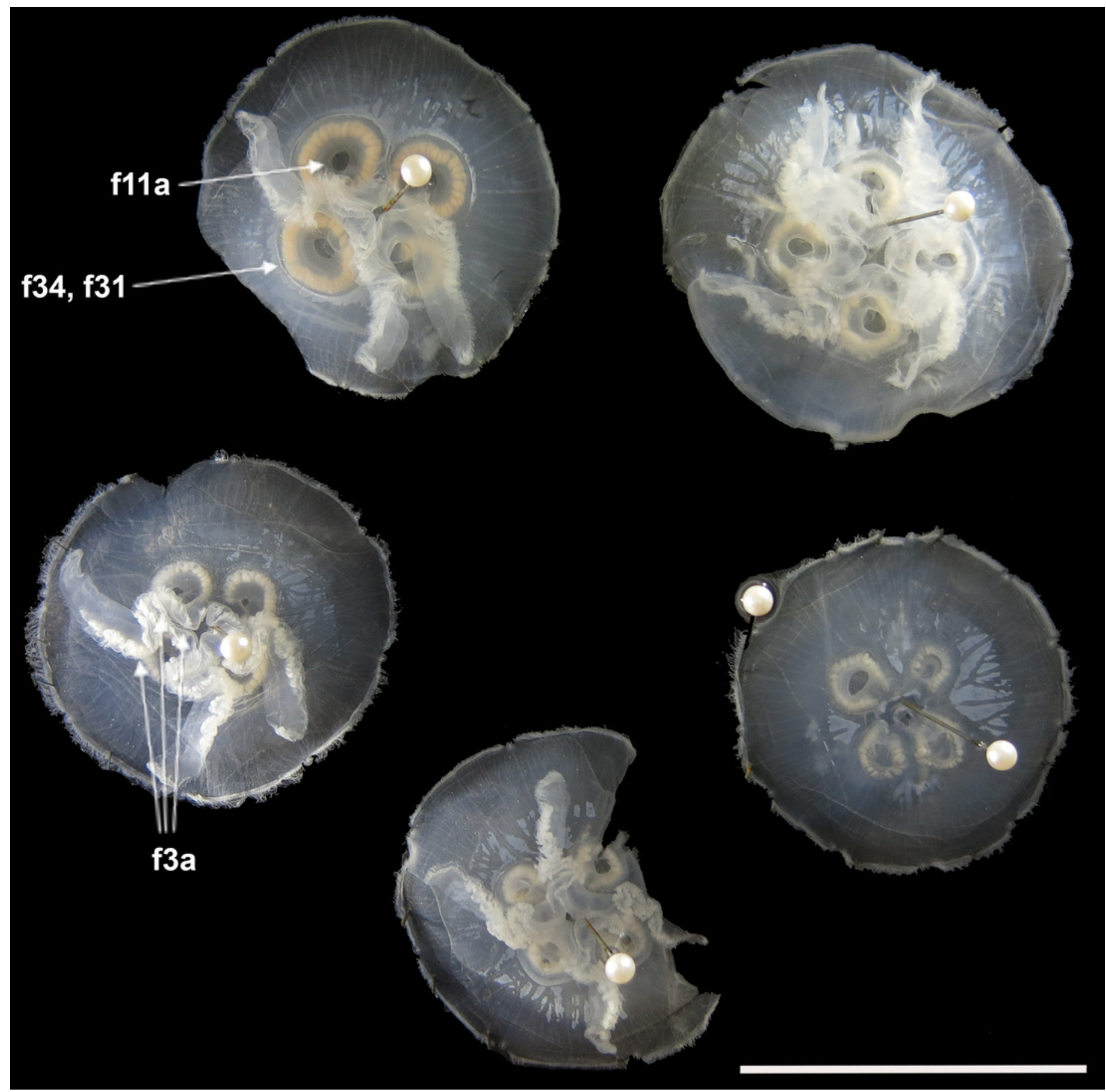




\section{Figure 3}

Multidimensional scaling (MDS) of morphological features with estimation of missing data.

Specimens are depicted in black, as geographic locality or institution, and features appear in red, as weighted averages of their contributions. Specimens highlighted in blue from the northeastern USA appear in Fig. 2 (YPM29380) and those highlighted in green from northeastern Canada and the southwestern USA in Fig. 5 (USNM30988 and USNM92912-5, respectively). One of the specimens highlighted in orange from the aquarium at Discovery Place, USA, appears in Fig. 6A (DP3-4). One of the specimens in the black boxes from the Arctic appears in Fig. 6C (USNM 44243-2) and the specimen from northwestern Canada in the grey box appears in Fig. 6D (USNM92913-1). Specimens highlighted in orange are Aurelia coerulea, in pink are Aurelia cebimarensis sp. nov. and in red Aurelia mianzani sp. nov., identified based on genetic sequences (Table S4). See Fig. S1 for the exact correspondence to specimen vouchers, Table 1 for institution acronyms and Fig. 1, Tables S1-S3 for more information on specimens measured and morphological features. 


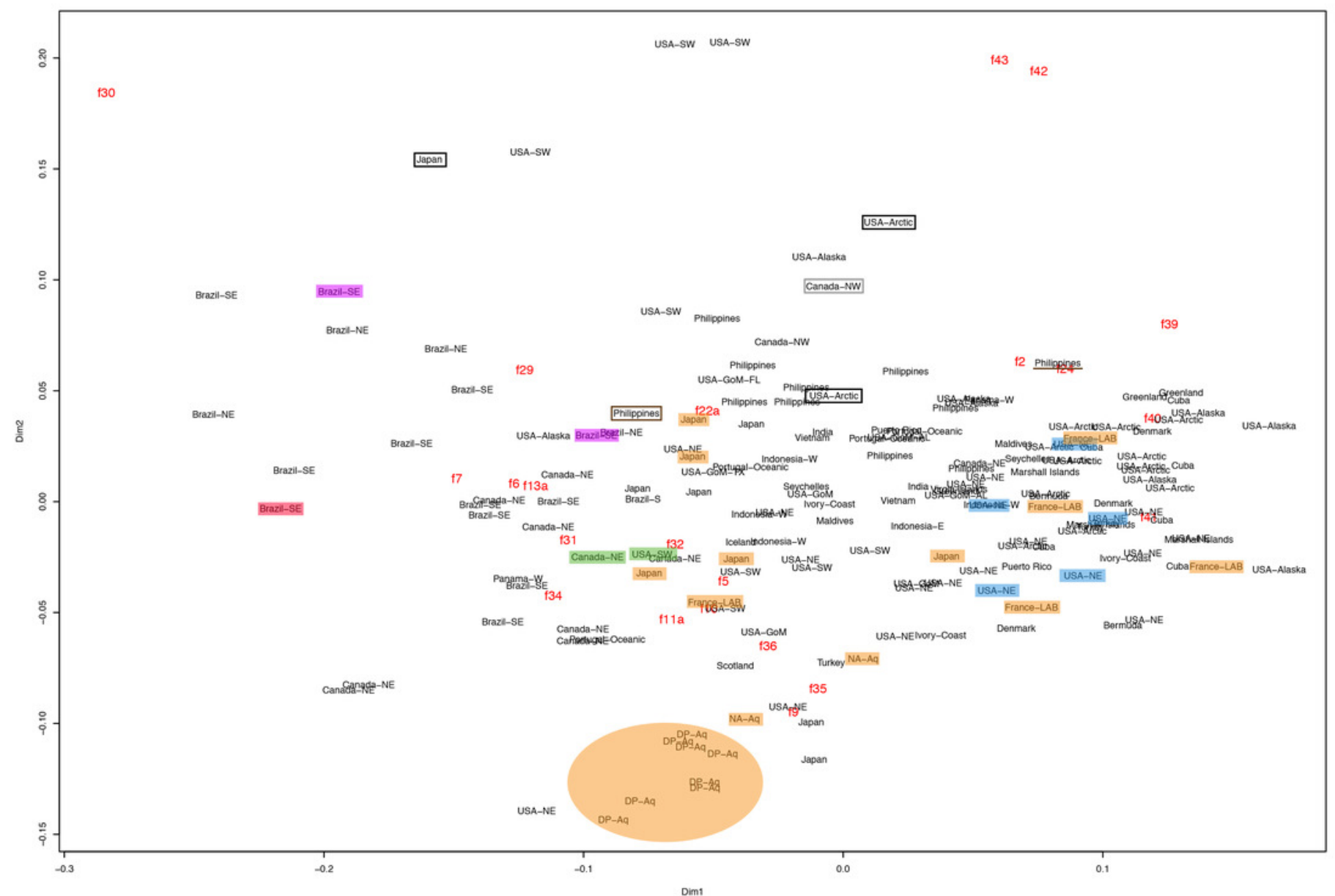




\section{Figure 4}

Multidimensional scaling (MDS) of morphological features without estimation of missing data.

Specimens are depicted in black, as geographic locality or institution, and features appear in red, as weighted averages of their contributions. Specimens highlighted in blue from the northeastern USA appear in Fig. 2 (YPM29380) and those highlighted in green from northeastern Canada and the southwestern USA in Fig. 5 (USNM30988 and USNM92912-5, respectively). One of the specimens highlighted in orange from the aquarium at Discovery Place, USA, appears in Fig. 6A (DP3-4). One of the specimens in the black boxes from the Arctic appears in Fig. 6C (USNM 44243-2) and the specimen from northwestern Canada in the grey box appears in Fig. 6D (USNM92913-1). Specimens highlighted in orange are Aurelia coerulea and in pink Aurelia cebimarensis sp. nov., identified based on genetic sequences (Table S4). See Fig. S2 for the exact correspondence to specimen vouchers, Table 1 for institution acronyms and Fig. 1, Tables S1-S3 for more information on specimens measured and morphological features. 


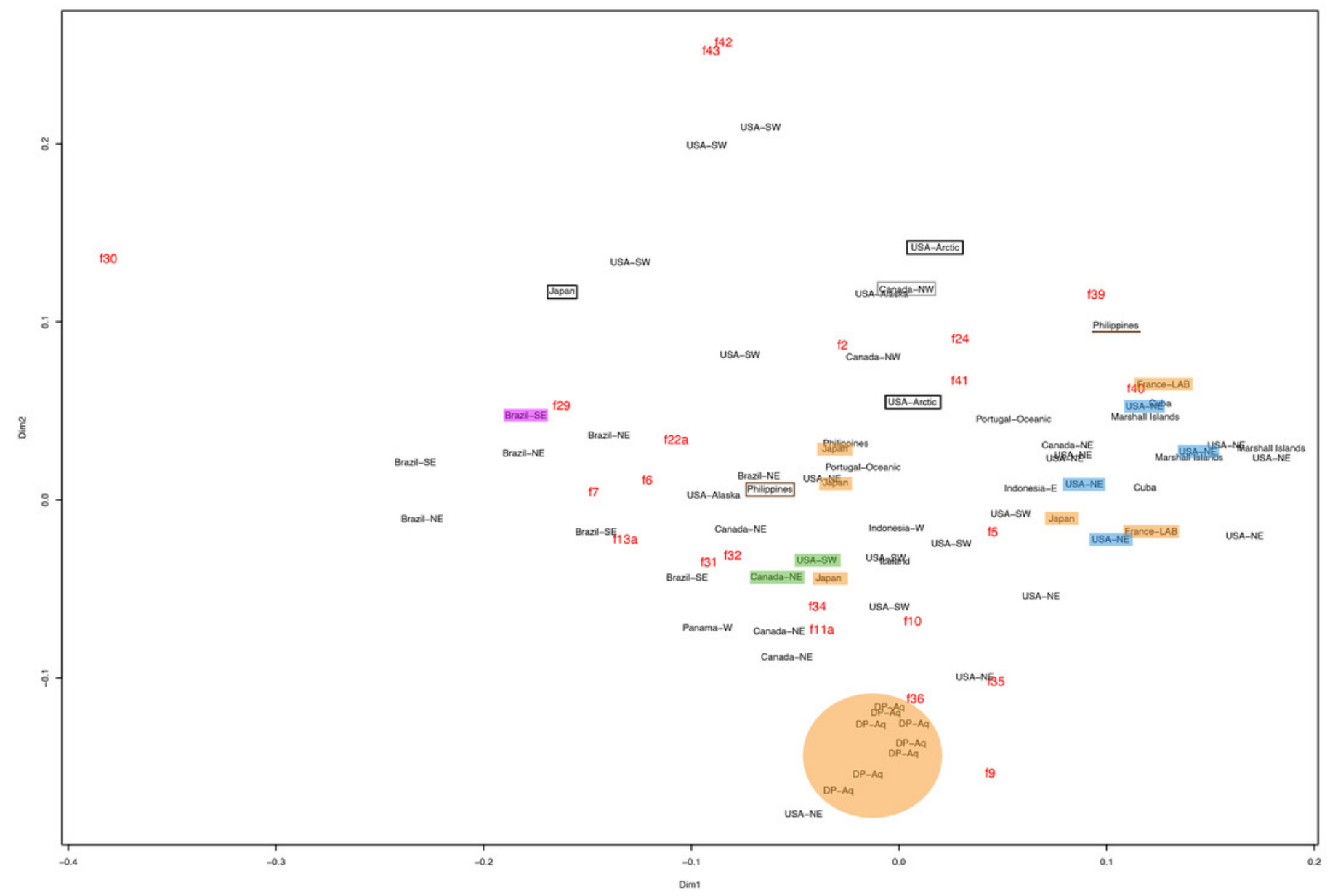




\section{Figure 5}

Aurelia medusae from northeastern Canada (USNM 30988) (A-B) and the southwestern USA (USNM 92912-5) (C-D) (highlighted in green in Figs. 3-4, S1-S2).

The images show an interradial sector, from the gastric pouch to the bell margin, and emphasize similarities on the oral arms ( $f 5$ and f7), the size of the sub-genital pores (f11a) and the branching pattern of radial canals (f43). For more details, see Fig. 1 and Tables S1S3. Scales $=1 \mathrm{~cm}$. 

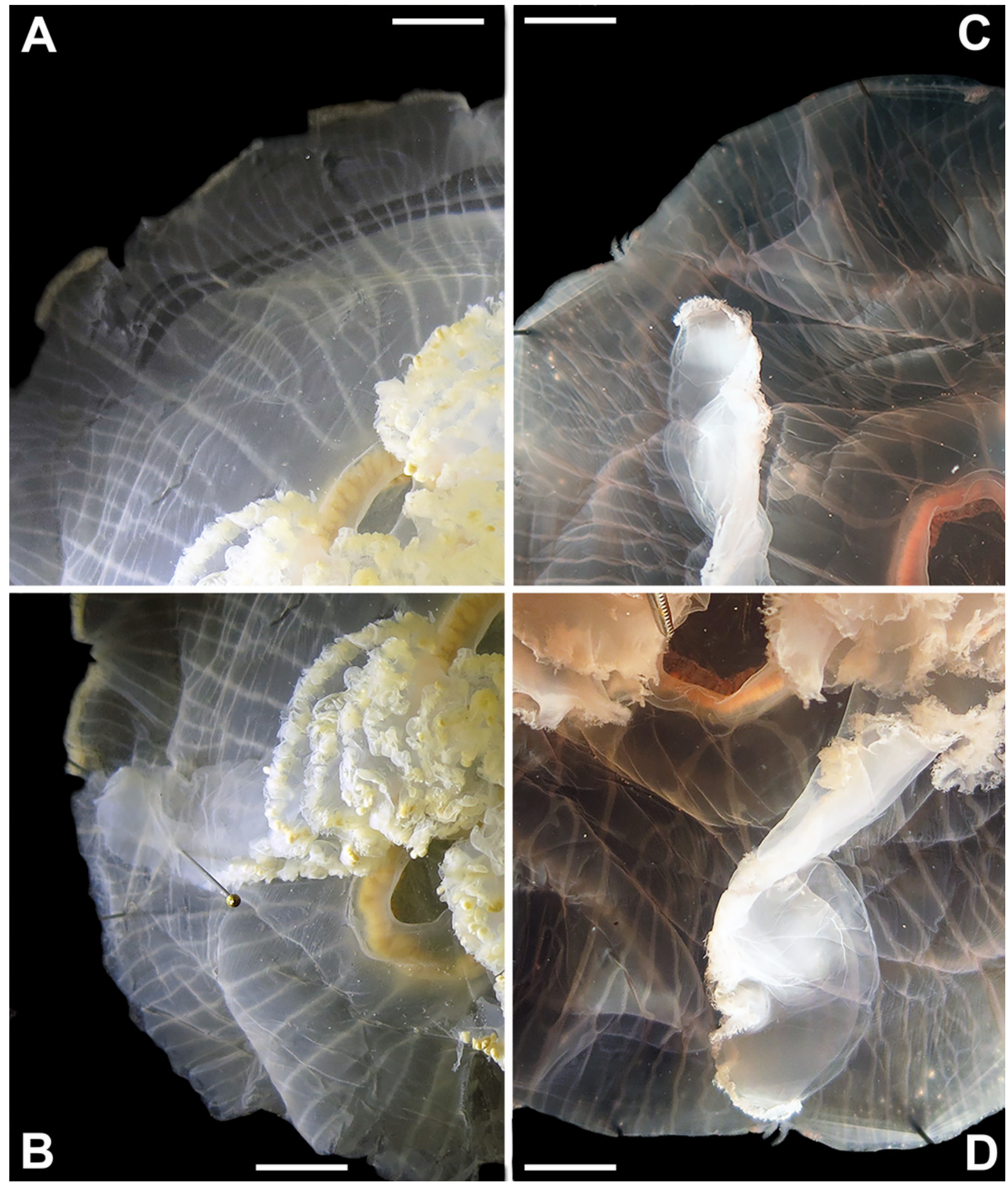


\section{Figure 6}

Aurelia from the aquarium at Discovery Place, USA (DP3-4) (A), Brazil (LAB08) (B), the Arctic (USNM 44243-2) (C) and northwestern Canada (USNM 92913-1) (D) (some of these are highlighted in Figs. 3-4, S1-S2).

The images illustrate some morphological features that are distinguished in these specimens, such as distance between proximal edges of opposing gastric pouches ( $\mathrm{f} 9$ ) and between proximal tips in each gastric pouch ( $\mathrm{f} 35)(\mathrm{A})$, rhopaliar (f29) and non-rhopaliar indentations (f30) (B), number of perradial (f42) and interradial branching points (f43) (C), and number of interradial terminations (f40) (D). For more details, see Fig. 1 and Tables S1-S3. Scales $=2$ $\mathrm{cm}$. 

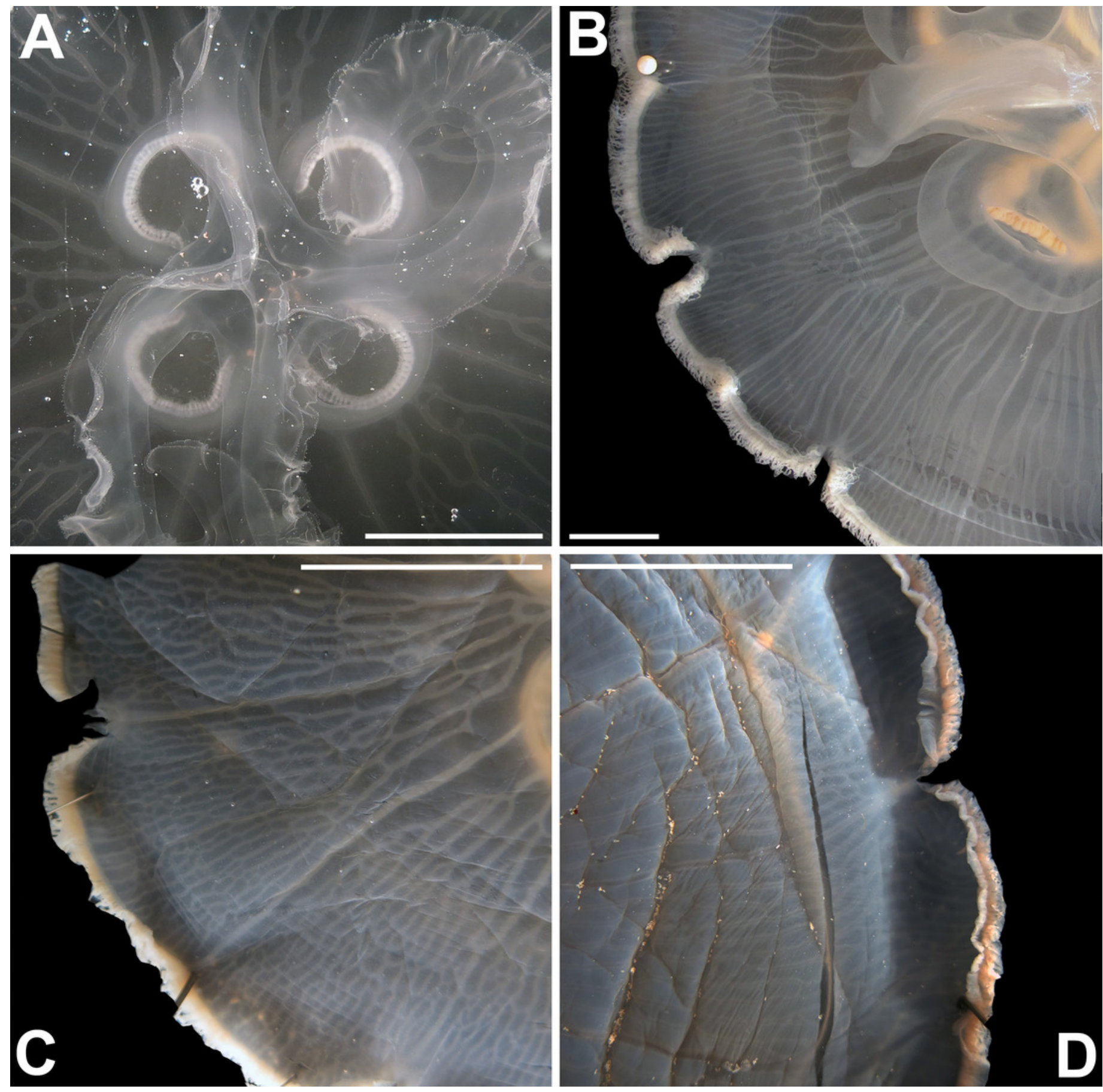


\section{Figure 7}

Aurelia coerulea from the Mediterranean (collected from the field) (A-B) and from lab cultures (originally from the North Sea) (C-D).

Some morphological differences can be perceived when comparing the medusa's overall appearance $(A, C)$, such as the oral arms and gastric pouches. The hood that covers the rhopalia is also different, triangular in Mediterranean specimens (B) and rounded in cultured specimens (D). A-B, bell diameter (f1) $=12.5 \mathrm{~cm}$ (images A and B were adapted from Scorrano et al., 2016); C-D, f1 $=7.5 \mathrm{~cm}$. 


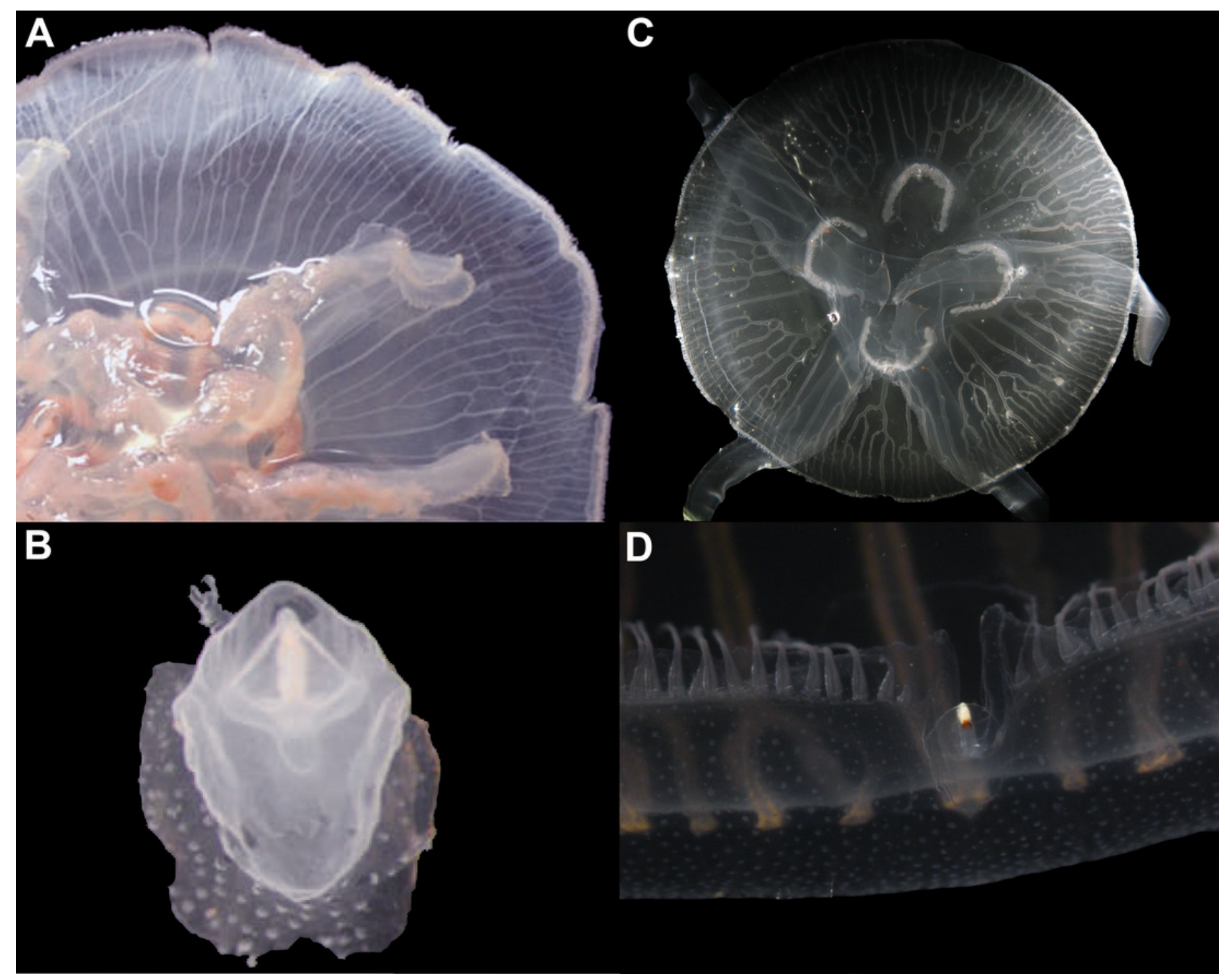


Figure 8

Comparison of morphological features measured from seven to ten Mediterranean specimens (Table 2 from Scorrano et al., 2016) and from two lab-cultured medusae of Aurelia coerulea

Averages and standard deviations are presented for each morphological feature, for which a Welch's t-test returned significant differences between Mediterranean and lab-cultured specimens for all features $(p<0.05)$. For references on morphological features, see Fig. 1 and Table S3.

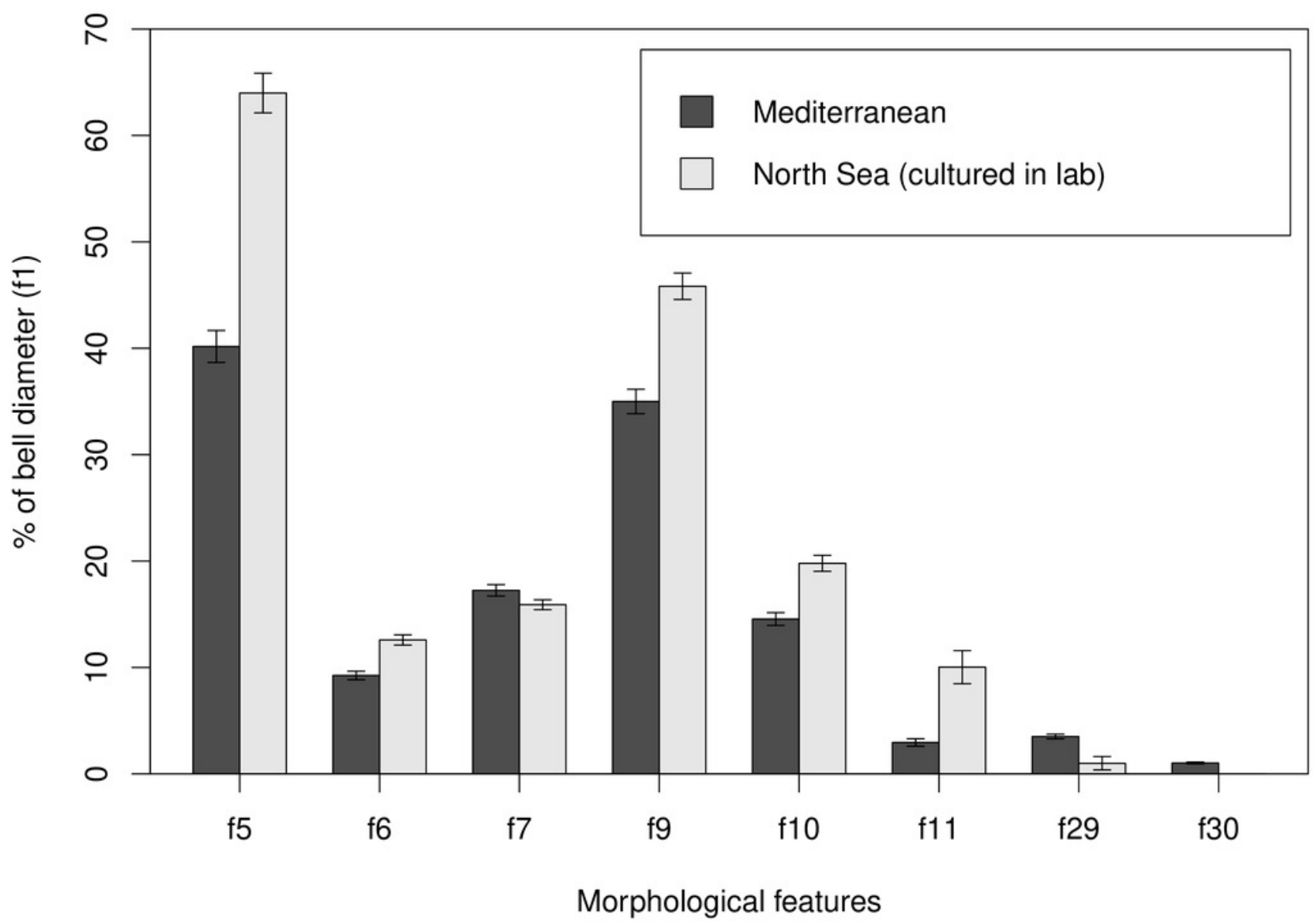




\section{Figure 9}

Concatenated phylogenetic analysis, indicating relationships between 28 Aurelia species hypotheses.

This analysis combined markers 16S, COI, ITS1 and 28S, reconstructing relationships under parsimony as the optimality criterion. Unambiguous synapomorphies for each species are represented as counts of each retrieved category (black are unique and non-homoplastic; red are unique and homoplastic; and blue are non-unique and homoplastic; see further details in Machado, 2015). Circles next to species names indicate the presence or absence of a genetic marker (following legend) and its respective synapomorphies (black = marker and synapomorphies present, grey $=$ marker present but synapomorphies absent, white $=$ marker absent). Numbers on nodes indicate Goodman-Bremer support values and colored circles represent bootstrap resampling frequencies (black $=\geq 95$, grey $=\geq 75$, absent $=$ $<75)$. Scale bar represents the number of nucleotide transformations. Table S4 contains further details on sequences used to reconstruct this phylogeny. A concatenated phylogenetic analysis was also performed under maximum likelihood as the optimality criterion and is available in Fig. S3. Single-marker phylogenies are presented in Figs. S4-S7. 


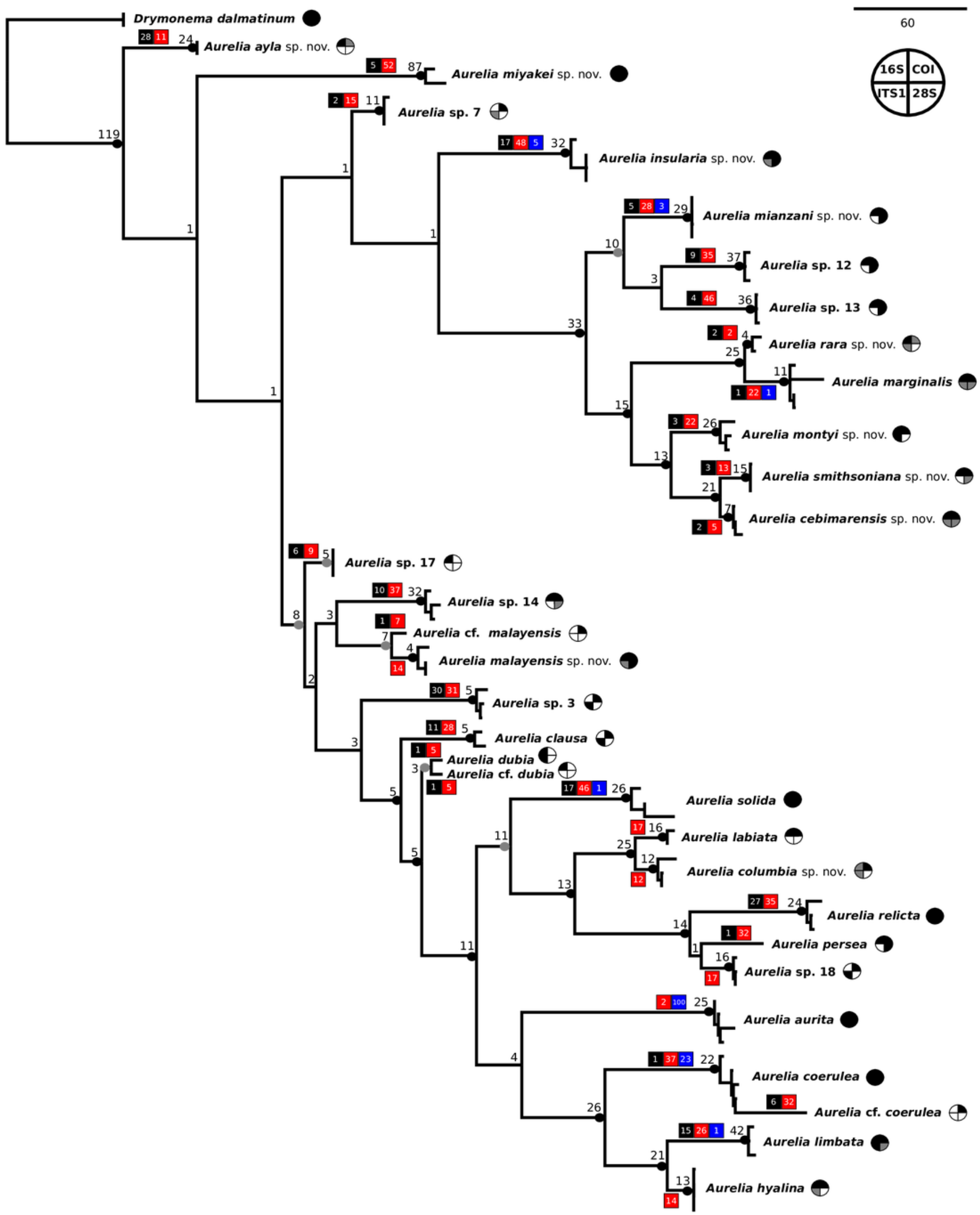




\section{Figure 10}

Sampling or type localities for Aurelia species treated herein.

Symbol shapes correspond to existing (square), resurrected (inverted triangle), new (diamond) and undescribed (circle) species. Oceans where each species is distributed are indicated in circles next to species names in the inset concatenated phylogenetic tree (detailed in Fig. 9). Details on the distribution range of each species is described in the 'Systematic account' section and the precise localities of sequenced specimens are presented in Table S4.

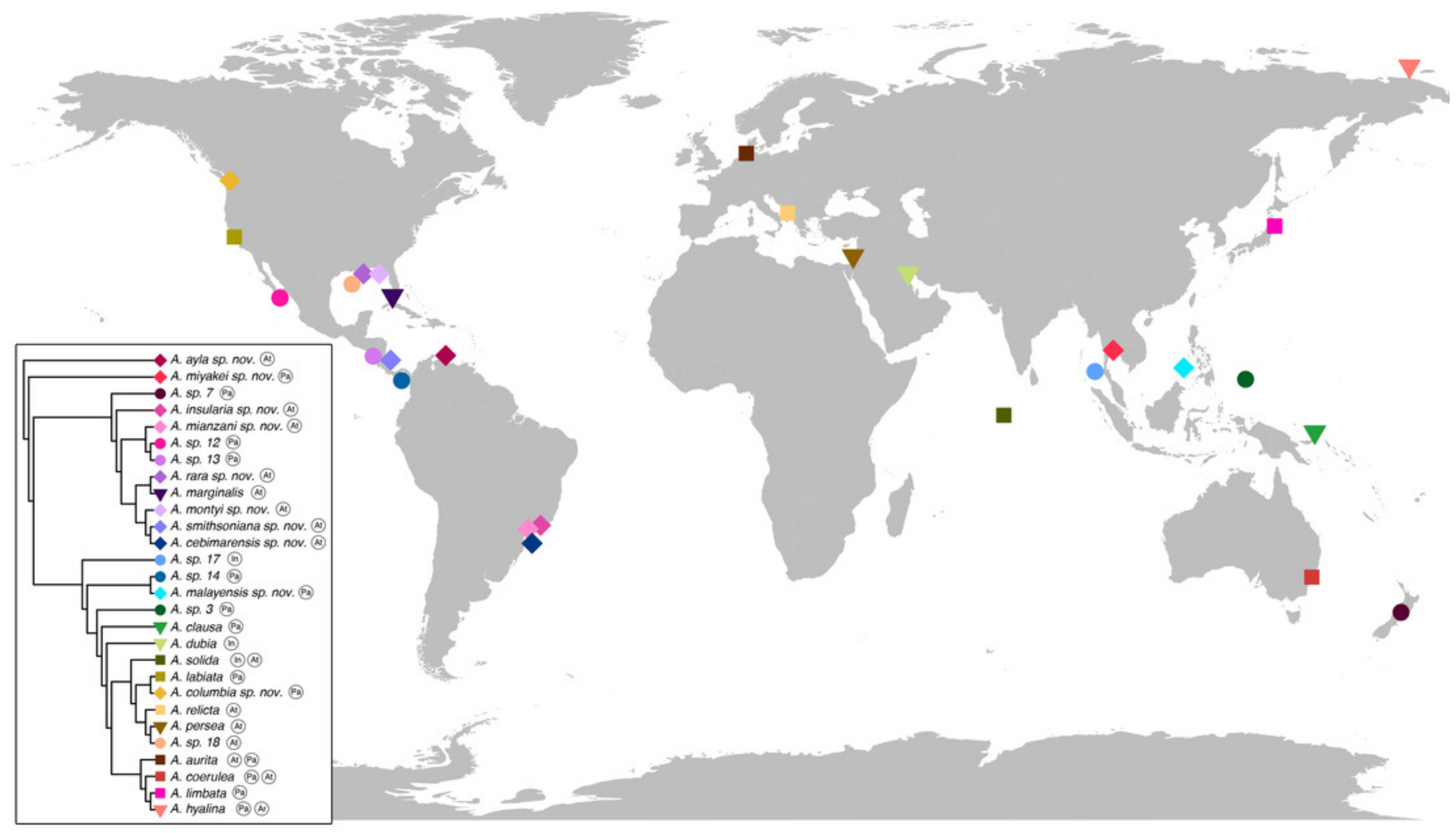


Figure 11

Frequency histograms of uncorrected pairwise distances (\%) from 16S, COI, ITS1 and $28 \mathrm{~S}$ alignments.

Intraspecific distances are represented in light-grey, while interspecific distances appear in dark-grey (see details in Table S7).

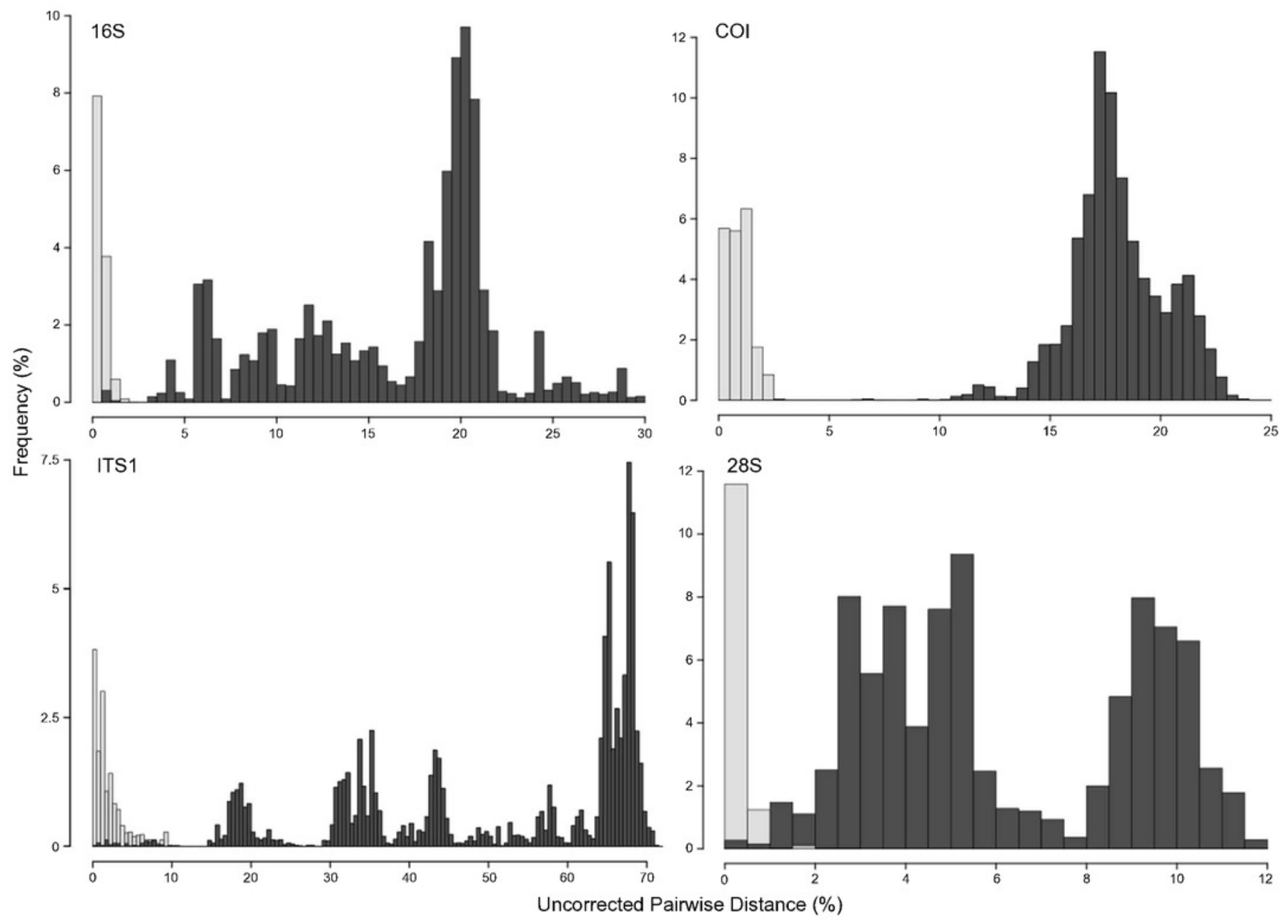




\section{Figure 12}

Comparison of rhopalium morphology observed in some Aurelia medusae.

The 90 - angled sense organ can be noticed in medusae from various localities, which includes the southwestern coast of the USA (USNM 92911-1, 92912-4) (A, B, respectively), the Atlantic Ocean off Portugal (USNM 58263-1) (C) and Aurelia solida (modified from Scorrano et al., 2016) (D). A, bell diameter (f1) $=13.45 \mathrm{~cm} ; \mathrm{B}, \mathrm{f1}=10.6 \mathrm{~cm} ; \mathrm{C}, \mathrm{f1}=5 \mathrm{~cm}$; , $\mathrm{f} 1=14.4 \mathrm{~cm}$. 


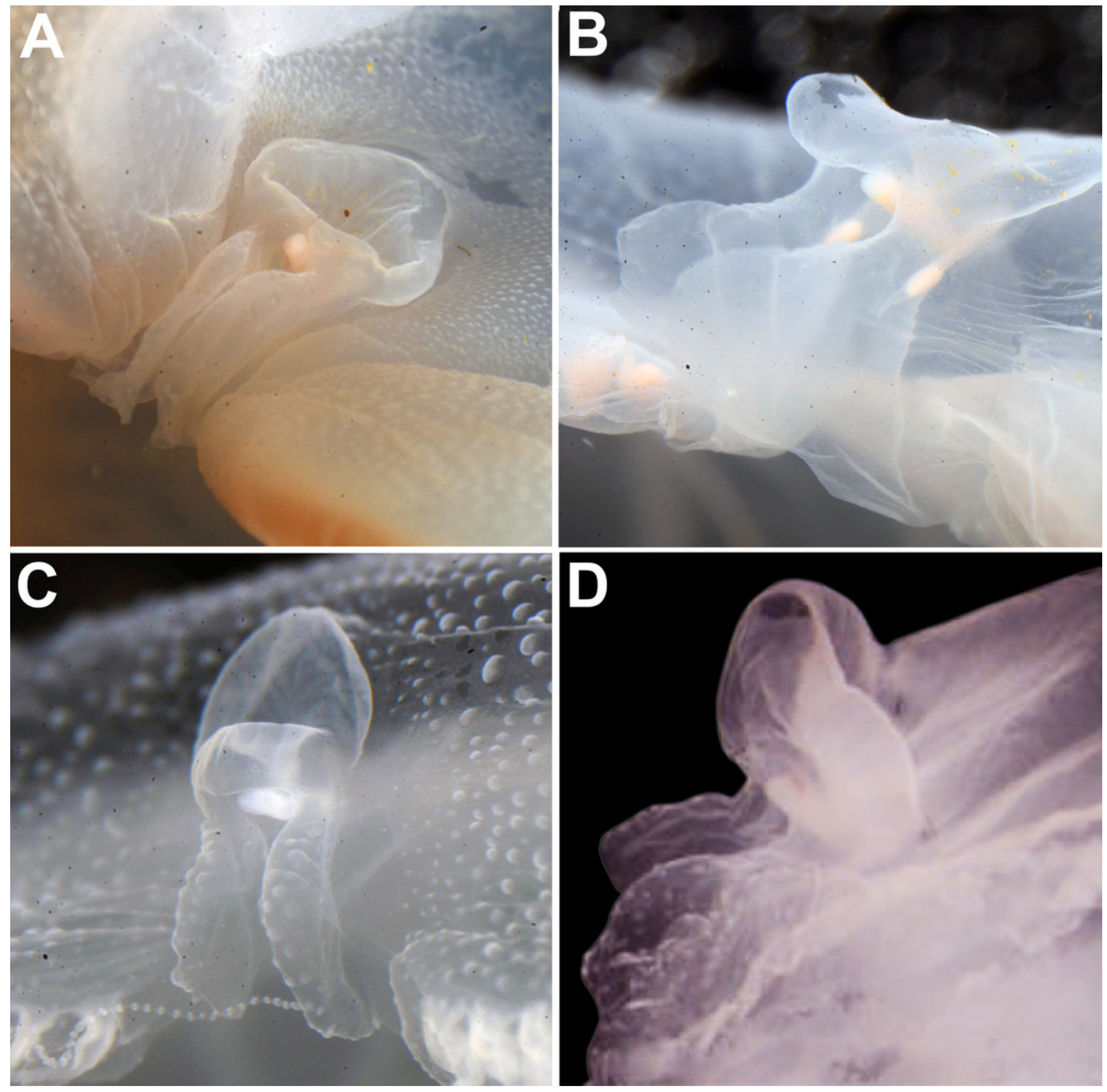




\section{Figure 13}

Comparison of manubrium morphology observed in two Aurelia medusae.

The prominent manubrium, which sideways almost reached the margin of the umbrella, can be noticed in medusae from distinct localities, which includes the Atlantic Ocean off Portugal (USNM 58284) (A) and the southwestern coast of the USA (USNM 92911-2) (B). Scales $=1$ $\mathrm{cm}$. 

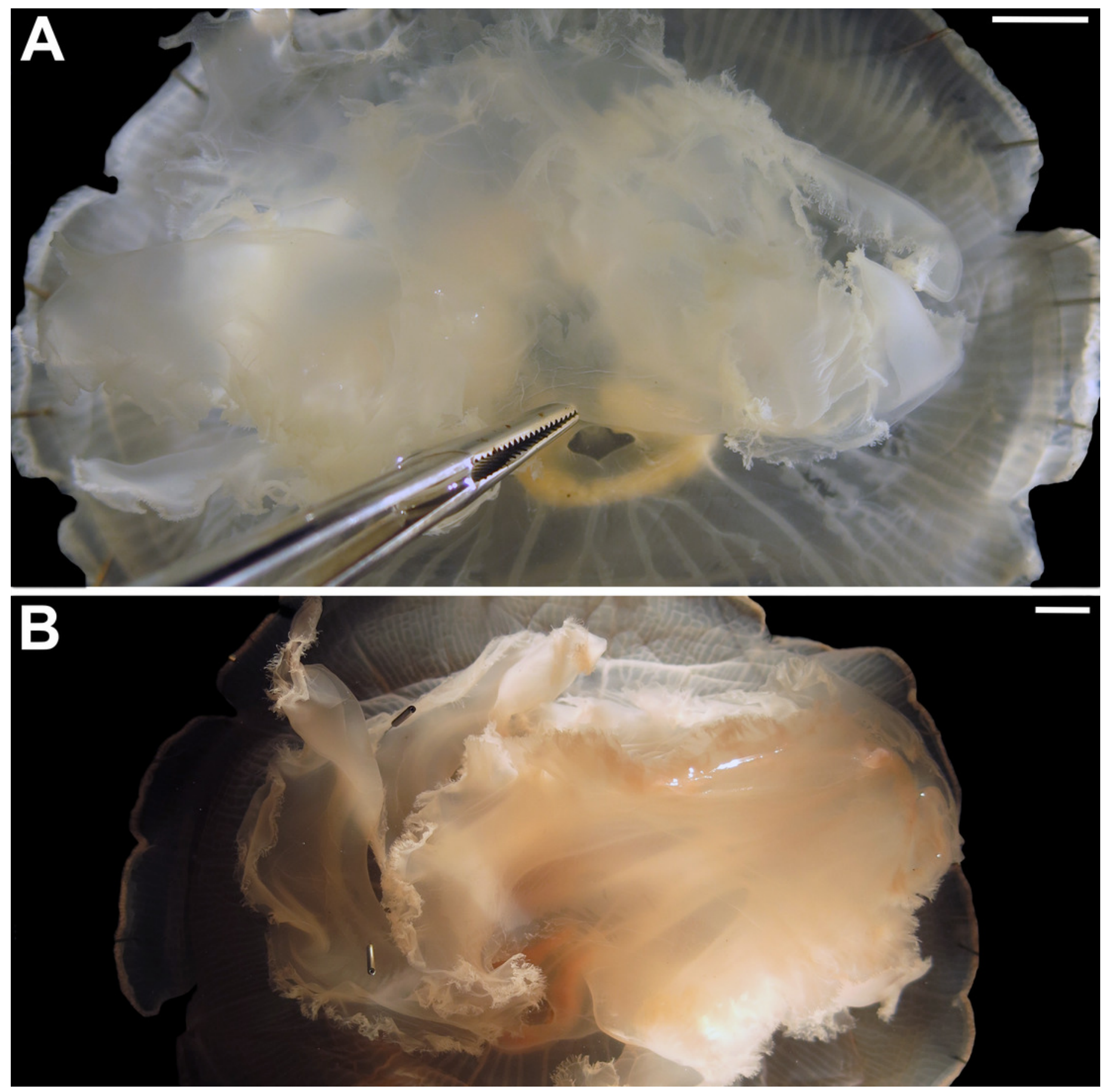


\section{Figure 14}

Taxonomic history of Aurelia species treated herein.

All studies that delimited and/or described a species for the first time were included, and each of these instances is highlighted in dark green. Mentions of other species in these studies are highlighted in light green, including the name that was used. Species are ordered as terminals of the concatenated phylogeny (Fig. 9). 


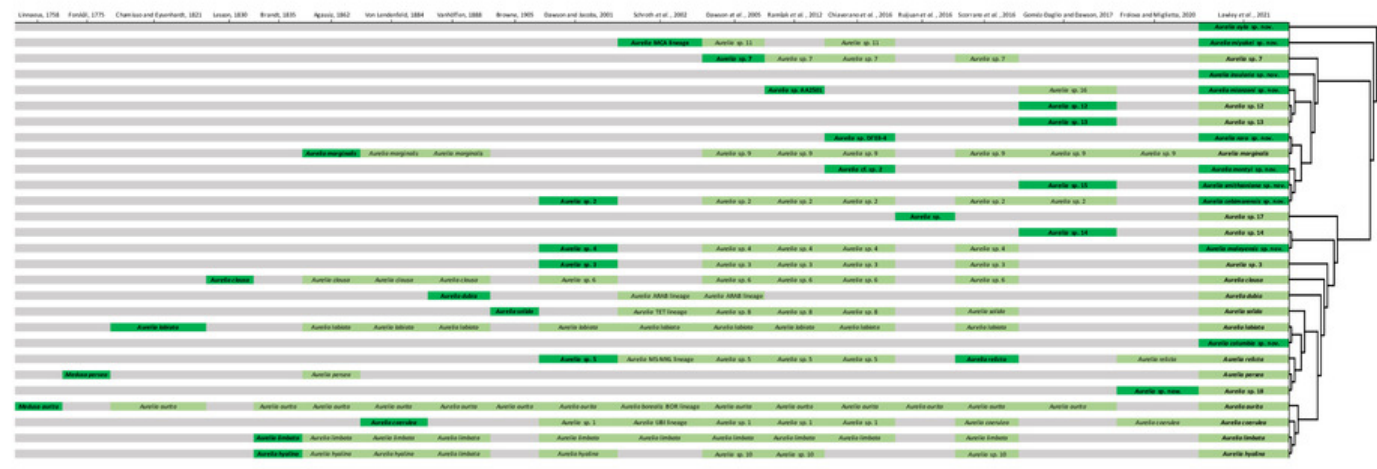

